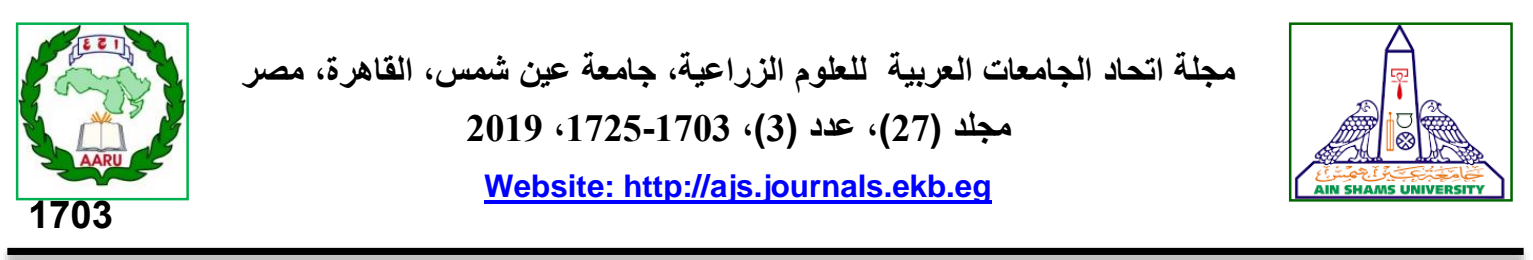

تقييم (قتصادي لصناعة تعبئة وتغليف البلح بمحافظة الوادي الجديد (دراسة حالة)

[138]

\author{
إلهام محمد سيد أحمد" - محد عبد الصادق السنتربسي - عبدالله محمود عبدالمقصود \\ قسم الاقتصاد الزراعي - كلية الزراعة - جامعة عين شمس - ص.ب 68 6د حدائق شبرا 11241 - القاهرة - مصر
}

*Corresponding author: elham.yazed@yahoo.com

Received 27 June, $2019 \quad$ Accepted 4 August, 2019

التعرف على كل من عدد المصانع وأهميتها النسبية

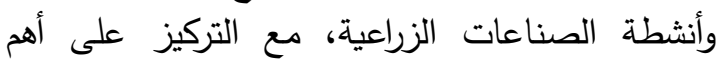

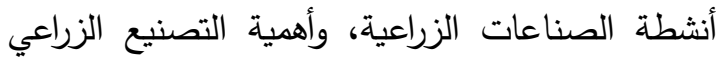

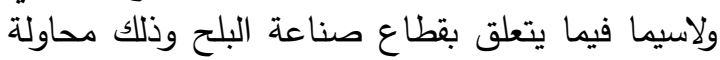

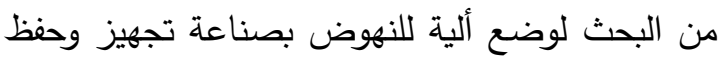

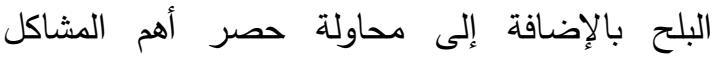

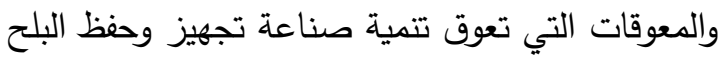
في محافظة الوادي الجديد لتنمية هذا القطاع عن تصنية

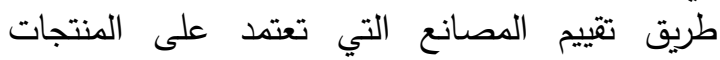

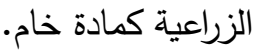

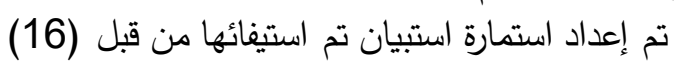

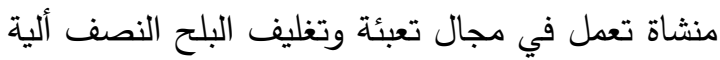
حيث جمعت المعلومات الخاصة ببيانات البحث خلئل خلال

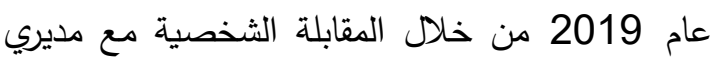

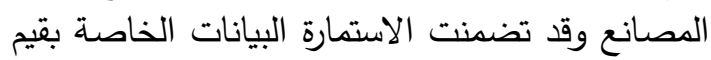
الإنتاج والمواد الأولية والأجور والمستلزمات العات السلعية

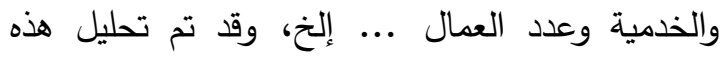
البيانات باستخدام المعايير المالية والاقتصادية، و تبين وتين

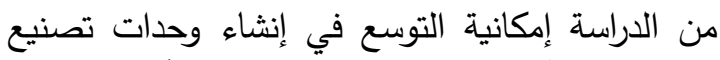
البلح حيث أنها تحقق ربحا تجاريا سنوياً يتراوح بين (167.30-6.9 مليون جنيه تمثل نسبة ربحية تجارية

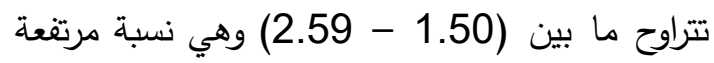
تعكس مدى ربحية هذا النشاط الانتاجي، بينما تراوح عائد

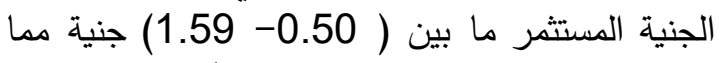
يرشد إلى كفاءة تلك الصناعة اقتصادياً، بينما تراوحت

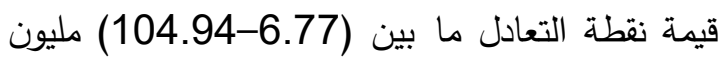
جنية، بينما أظهرت نسبة حد الامان الانتاجي التي لماني

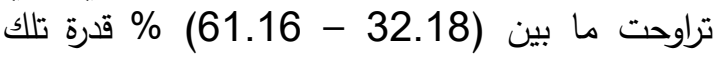

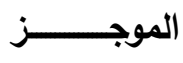

تسهم المشروعات بمختلف أحجامها وأنواعها في

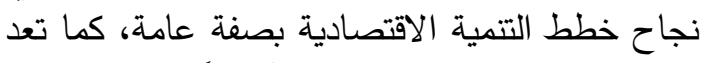

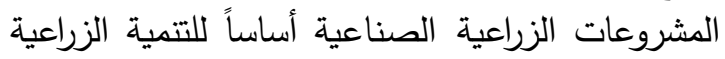

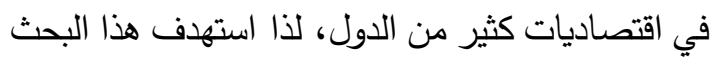
التعرف على الجدوى الاقتصادية لأحد الأنثطة الإنتاجية الإنيات

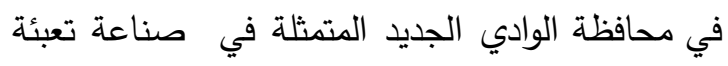

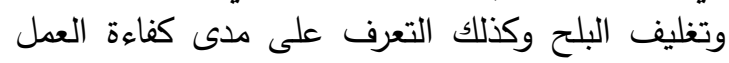
بالوحدات التصنيعية ومدى إمكانية التوسع في إنشائها مستقبلا بالإضافة إلى التعرف على النى الأثار المترتبة على التى التى إنشاء تلك الوحدات.

تتمثل مشكلة البحث في أن صناعة تعبئة وتغليف البـاء

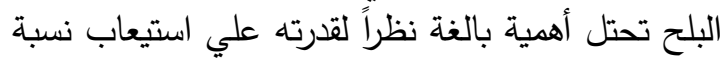

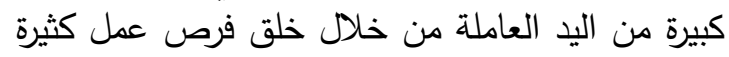

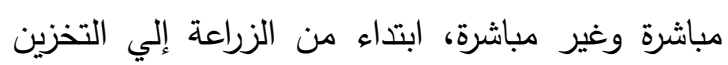

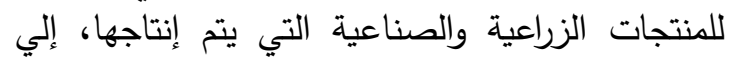

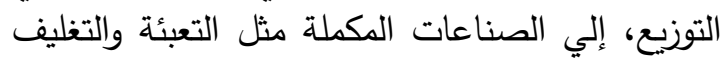

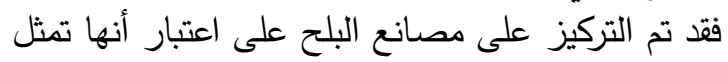

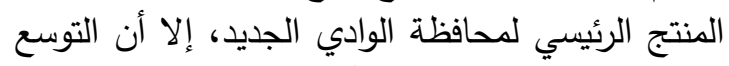

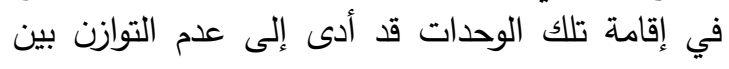

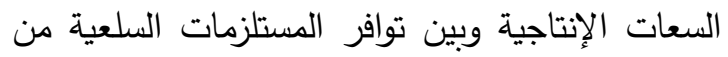

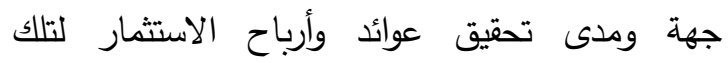

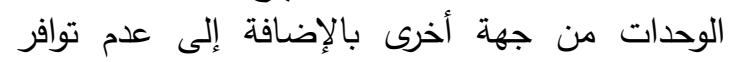

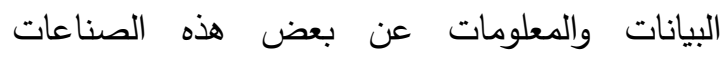
الزراعية القائمة بتلك المحافظة.

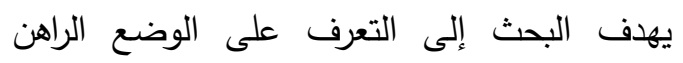
للتصنيع الزراعي بمحافظة الوادي الجديد من خلال الترف لرف 
وتصدر التمور المصرية الى أسواق 42 دولة يأتي على رأسها اندونيسيا والمغرب وماليزيا وبنجلاديش وتايلاند، كما تم فتح أسواق جديدة بأفريقيا وآسيا

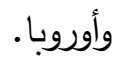

ونظراً لما يتميز به محصول البلح من طبيعة غضة

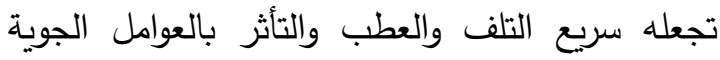

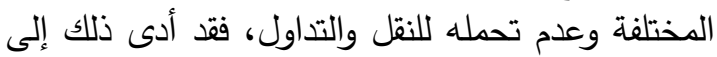

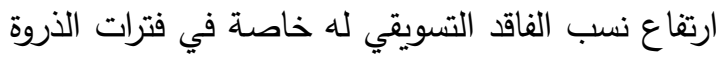

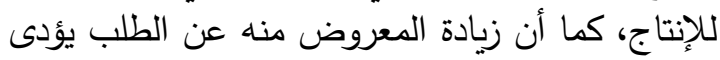

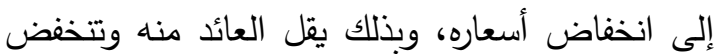

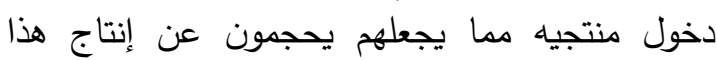
المحصول وبالتالي عدم الوفاء باحتياجات المصانع من لناج لنان

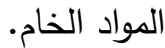
ومما لا شك فيه إن الخروج من الوادي القديم

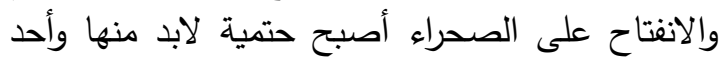

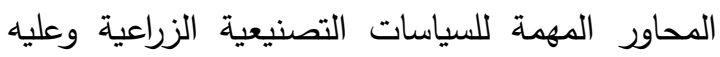

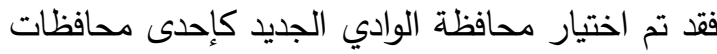
الحدود الصحراوية الواعدة، ذات الأولوية التصائ التصوى في

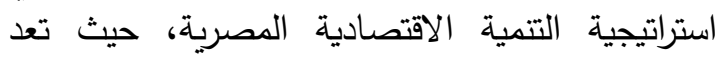
محافظة الوادي الجديد أكبر المحافظات من حيثة الكادية المساحة على مستوى الجمهورية حيث تبلغ مساحتها حوالي 440 ألف كيلومتز مربع تمثل نحو 44\%ة 68 من إجمالى مساحة كل من من الجمهورية والصحراء الغربية على الترتيب. كما تعُُ محافظة الوادي الجديد الأولى في إنتاج التمور حيث تتنج ما يزيد عن وذلك من خلال نحو 2 مليون نخلة مثمرة في مساحة تبلغ نحو19 ألف فدان، وقد بلغ إنتاج الدحافظة في من في

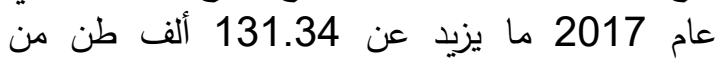
التمور الخام من أعلى الأصناف جودة. ورغم تعدد الأنثطة الاقتصادية بمحافظة الوادي الأناي

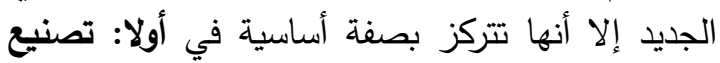
زراعي غذائي ويتضمن الصناعات التيات الغذائية القائمة

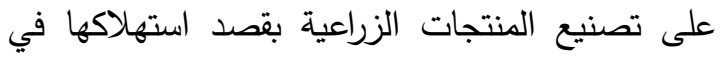
تغذية الإنسان مثل (صناعة طحن الحبوب والغلال ـ
الوحدات التصنيعية على مواجهة ظروف المخاطرة المحتملة من انخفاض الانتاج او انخفاض سعر المنتج. الكلمات الدالة: التصنيع الزراعي، التقييم المالي، حد الأمان، نسبة الهنافع للتكاليف، تعبئة وتغليف البلح.

\section{مقدمسة}

يعتبر التصنيع الزراعي من أهم التطاعات الصناعية التي يمكن أن تسهم في تحقيق الأمن التراعي

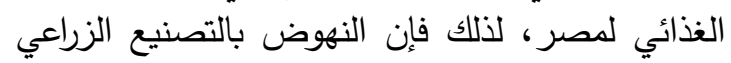

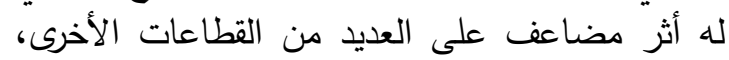

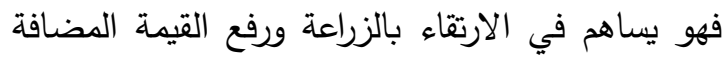
من المحاصيل الزراعية وتقليل الفاقد منها. ولتعظيم دور التصنيع الزراعي في الاقتصاد القومي التوني

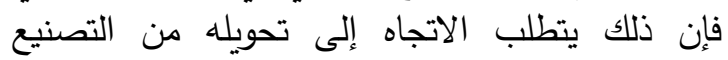
الزراعي الذى يقوم علي الفائض من الإنتاج الزراعي

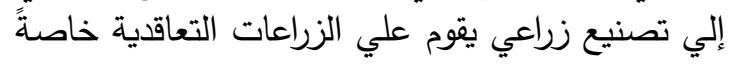

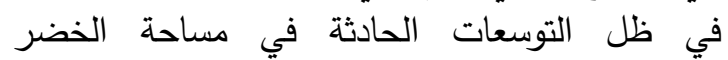
والفاكهة، والتي تحقتت من خلال عمليات الاستصلاح والتوسع في الأراضي الصحراوية الجديدة، والتي تتميز بودة منتجاتها من حيث الصاضئ الصفات الإنتاجية والتصديرية. وقد عرفت مصر النخيل في العصر الحجري

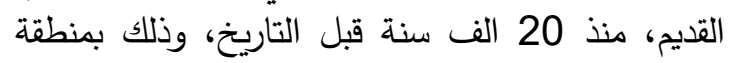

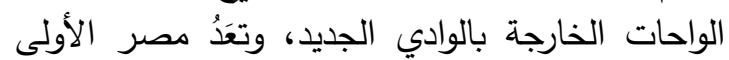

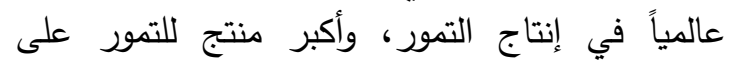
المستويين العببي والعالمي، حيث تنتج 18 بالمئة من العن

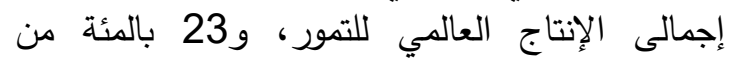

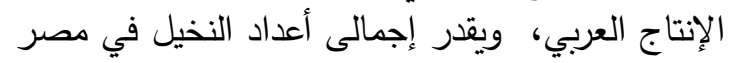

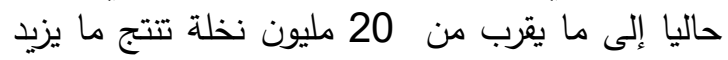

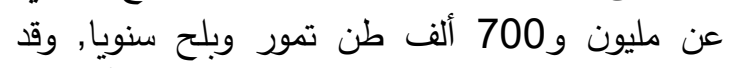
بلغت صادرات التمور المصرية خلال الربع الأول من

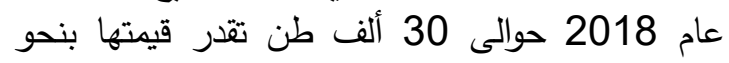
29.4 مليون دولار، حيث بلغ متوسط سعر الطن خلال الربع الأول من عام 20.4 كلار 2018 حوالى 980 دولار للطن. 
واجتماعيـة تعـود على المـواطن بالمحافظـة والاقتصــاد

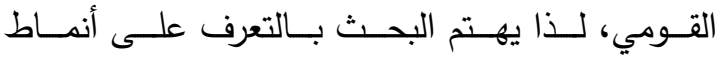

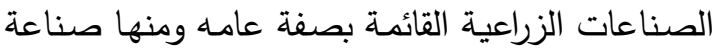

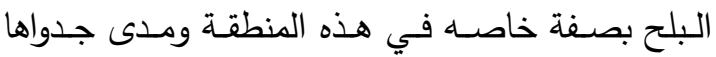

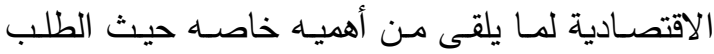

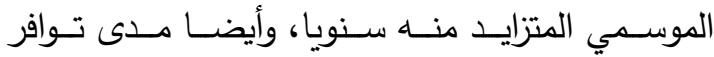

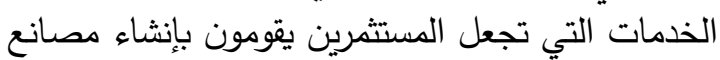

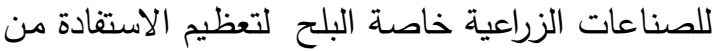

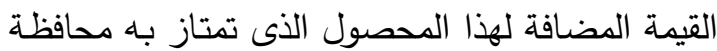

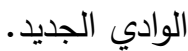

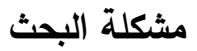

أخذ الاهتمـام بتتميـة محافظـة الوادي الجديد خـلال

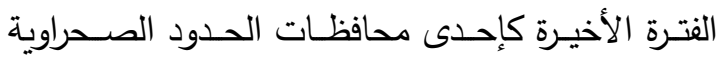

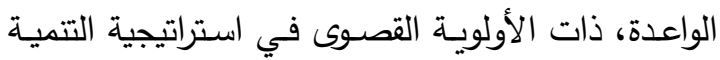
الاقتصادية المصرية، حيث تسعي الدولة إلي تتميتها

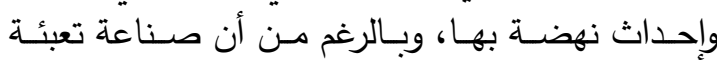

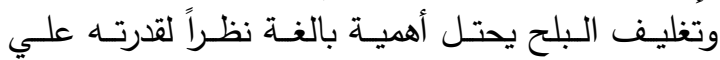

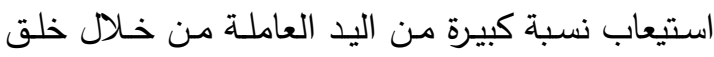

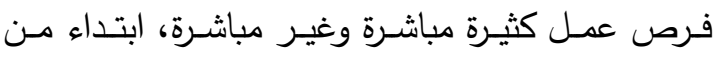

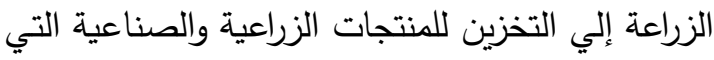

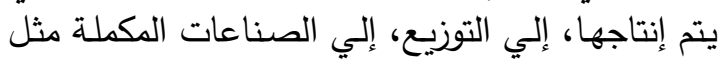

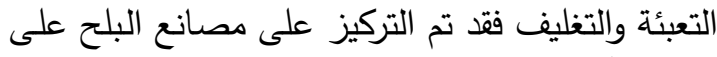

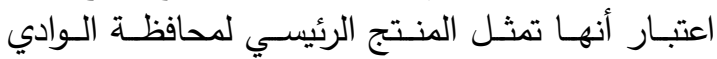

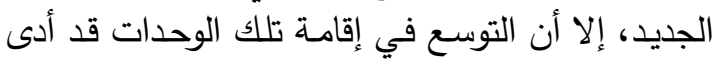

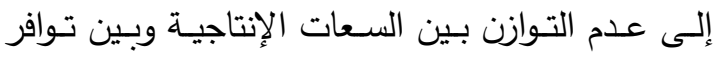

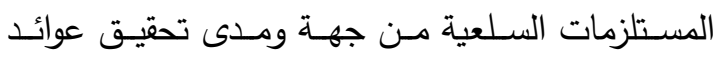

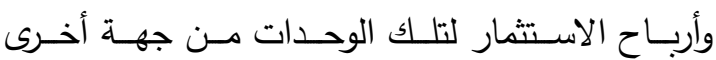

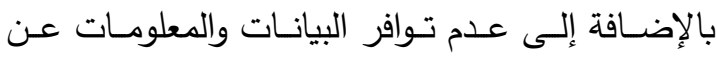
بعض هذه الصناعات الزراعية القائمة بتلك المحافظة.

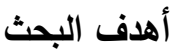

يهـدف البحـث إلـى التعـرف على الوضــع الـراهن

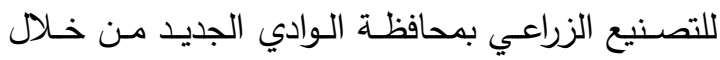

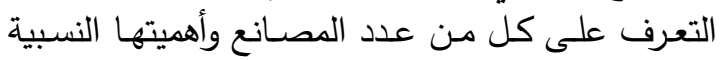

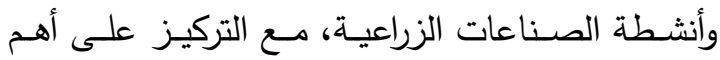

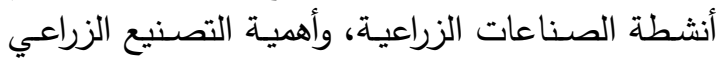

تعبئة وتغليف الفاكهة والخضروات تعبئة وتغليف

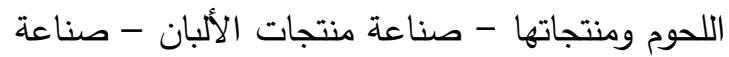
الزيوت والدهون)، ثانيا: تصنيع زراعي غياعة غناتير غذائي الأي

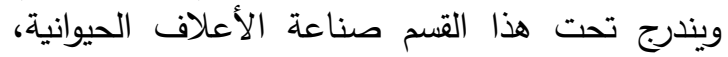
بالإضافة إلى صناعة السجاد والكليم وصناعة الجريد

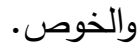

ويعد البلح من أهم المحاصيل الزراعية في المحافظة ويحتل مركز الصدارة بشكل متميز بين المنتجات الزراعية الأخرى حيث أنها لزئه يعد من التراث

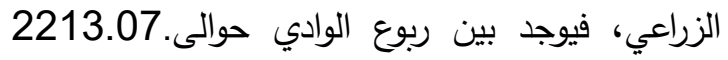

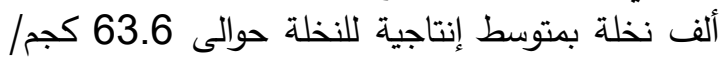
نخلة عام 2018 وتعد أصناف نخيل البلح بالوادي لندي الجديد من أهم الأصناف التي نالت صيتاً عالياً لجودة لإداف

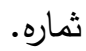

ونظرا لما يتمتع به محصول البلح الطازج والمصنع تمانح

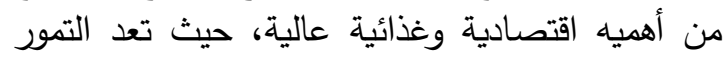
أحد محاصيل الفاكهة ذات القيهة الفية الغذائية العالية حيث العيث

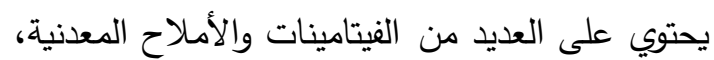

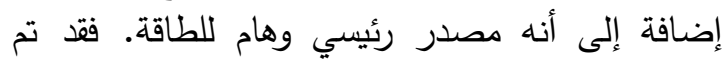

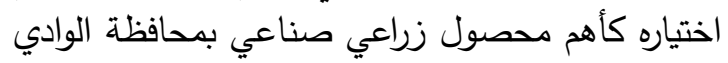

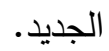

حيث تعد صناعة تعبئة وتغليف البلح لتسويقها داخليا وخارجيا من أهم الصناعات وأكثرها انتشاراً في تعنئ

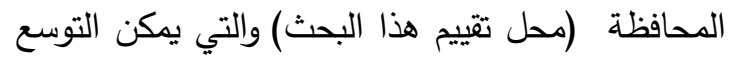

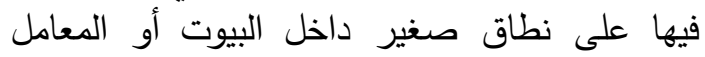

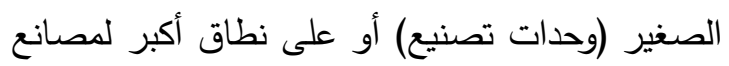

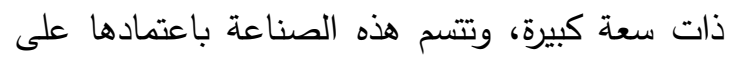

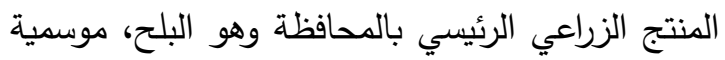

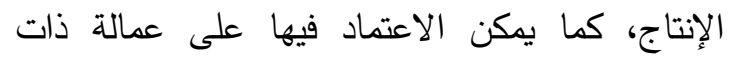

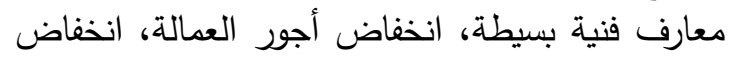
مستوى التقنية في التصنيع بغالبية المنثآت.

\section{أهمية البحث}

تأتى أهميـة البحث من أهميـة منطقة البحث، لمـا

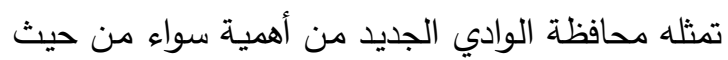

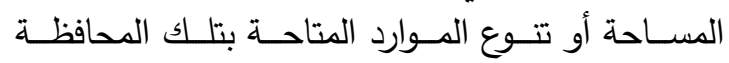

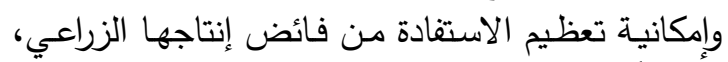

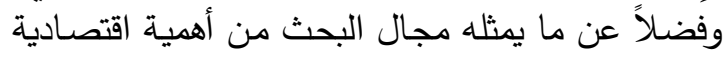


كمـا اعتمــــ البحـث على استخدام بعضض معـيير

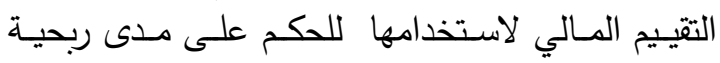

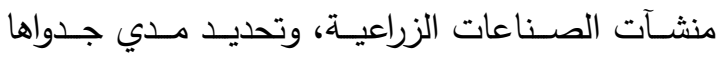

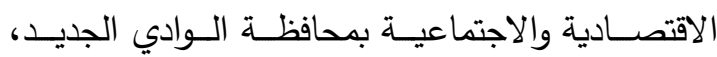

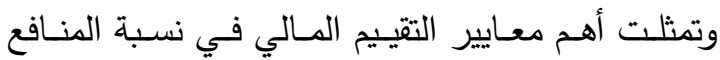

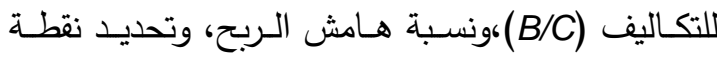

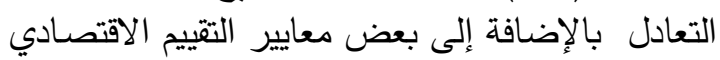
والاجتماعي الأخرى والمستخدمة في معالجة البيانات.

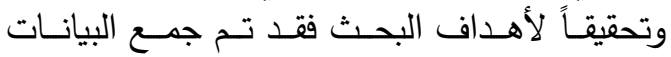

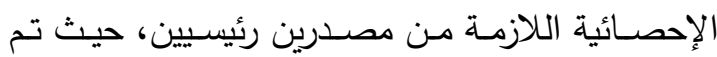

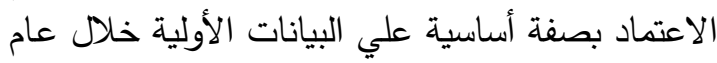

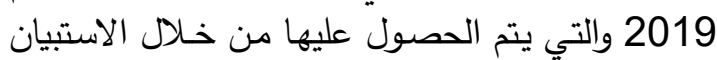

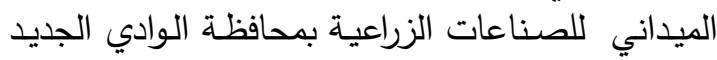

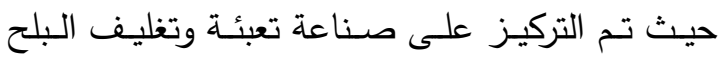

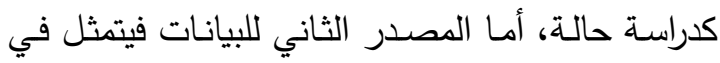

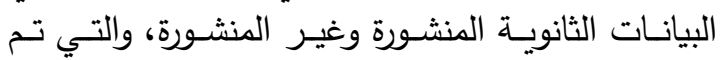

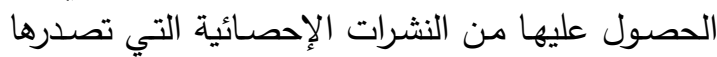

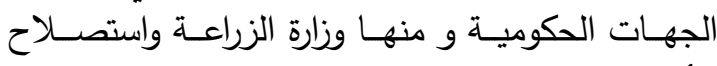

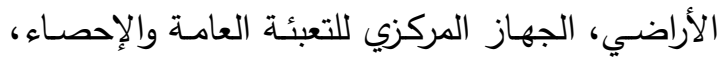

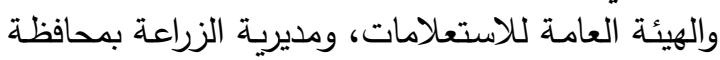

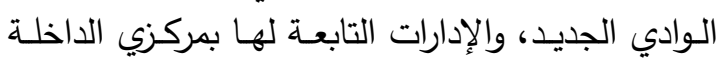

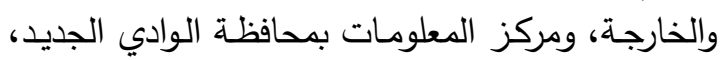
بالإضـافة إلـي العديد مـن الدراسـات والأبحاث العلميـة العادية ذات الصلة بموضوع البحث.

تطور المؤشـرات الإنتاجيـة لمحصـول البلح بمحافظة الوادي الجديد

1- تطور المساحة المنزرعة بالنخيل بالألف فدان

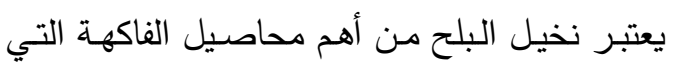

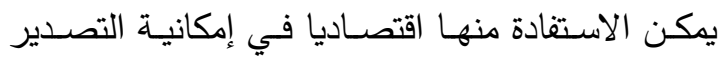

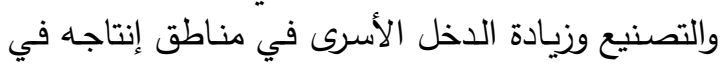

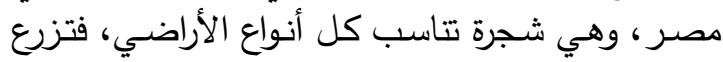

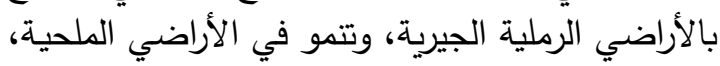

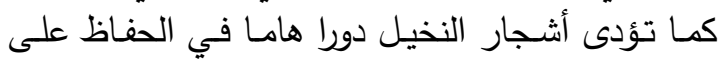

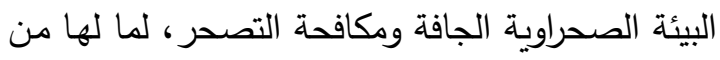

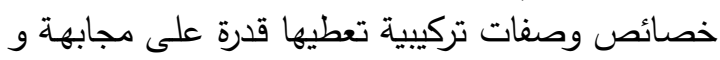

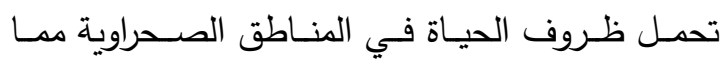

ولاسيما فيما يتعلق بقطاع صناعة البلح وذلك محاولة من البحث لوضع ألية للنهوض بصناعة فياعة تجهيز وحفظ

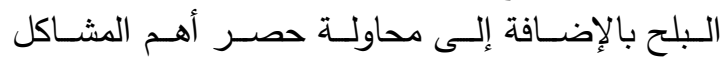

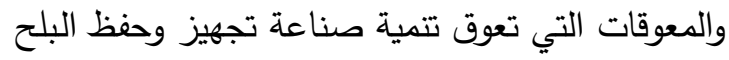

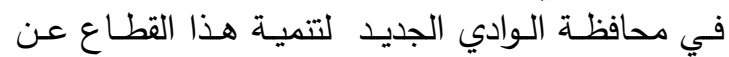

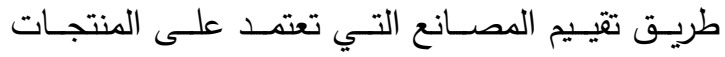

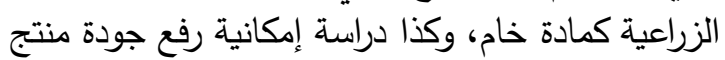

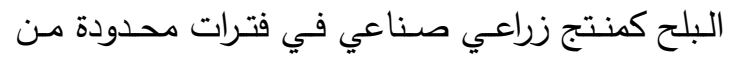

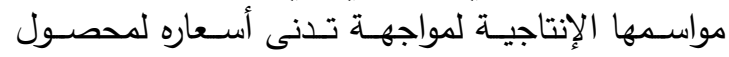

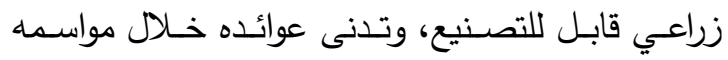

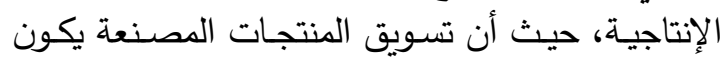

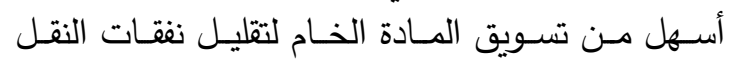

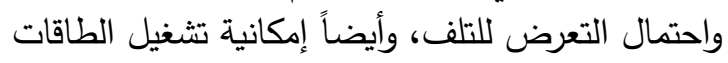

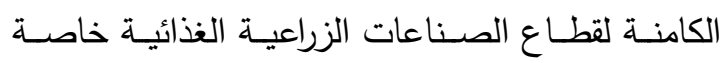
محصول البلح.

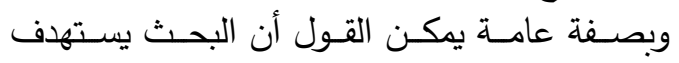

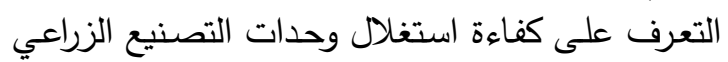

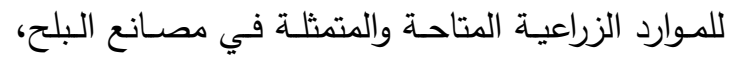

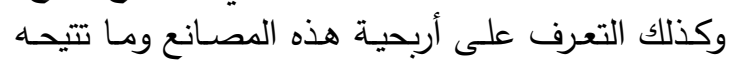

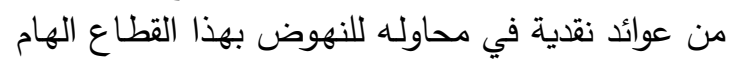

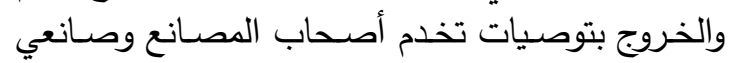

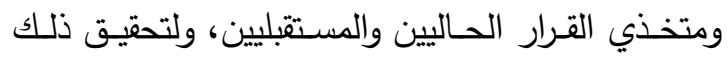
اهتم البحث بالنقاط التالية: 1- تقدير مؤشرات التقييم المالي والاقتصـادي لوحدات التالئ

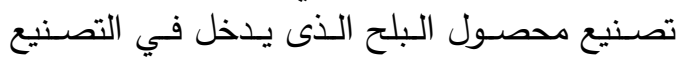
الزراعي بمحافظة الوادي الجديد. 2 ـ التعرف على أهم العقبات التي تواجه تلك الوحدات التوند التصنيعية. 3- بلورة أهم المقترحسات والتوصيات التي تسهحم في

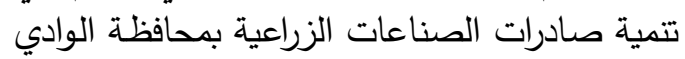

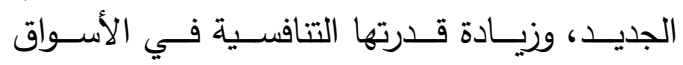

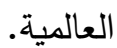
الطريقة البحثية ومصادر الحصول علي البيانات

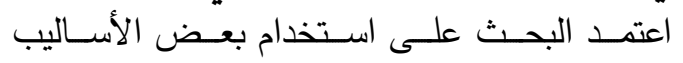

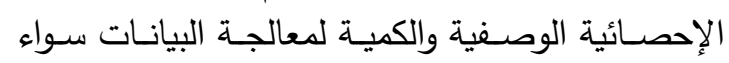

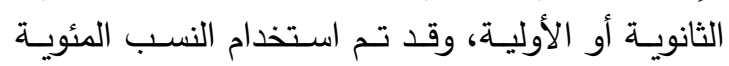

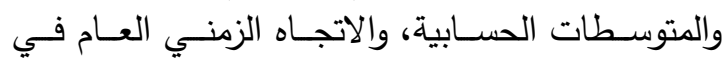

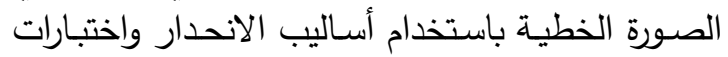
المعنوية وغيرها من الأدوات الإحصائية. 


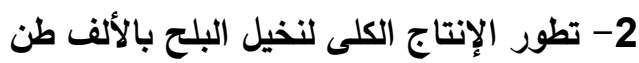

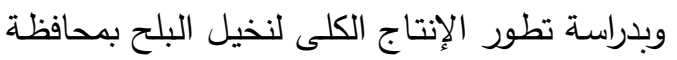

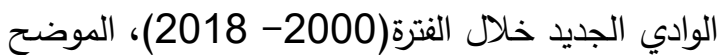
بالجدول رقم (1) تبين أنه أخذ في التذبذب بين الزيادة التيات

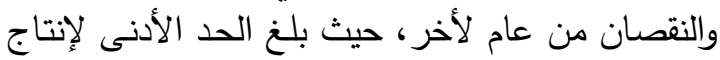

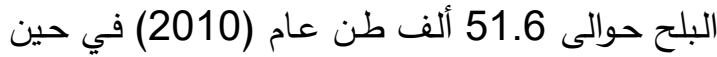
بلغ الحد الأعلى لإنتاج البلح بمحافظة الوادي الجديد

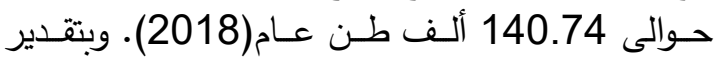

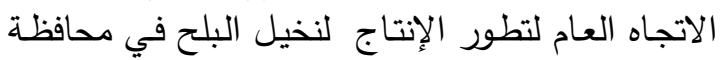

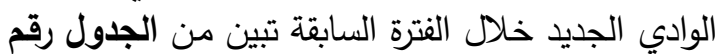

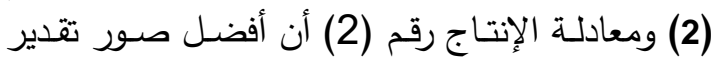

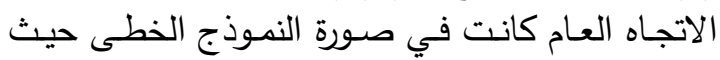
تحققت زيادة سنوية معنوية إحصائيا قدرت بنحو

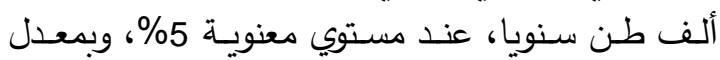
تغير بلغ نحو 5.06 \% من متوسط الإنتاج لنخيل

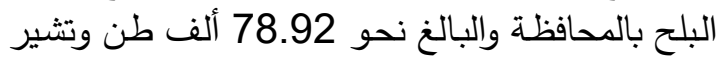

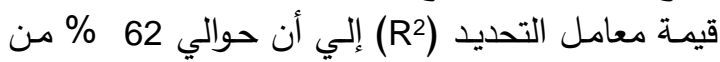
التغيرات الحادثة في إنتاج النخيل ترجي التئ إلي العوامل

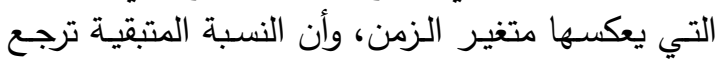

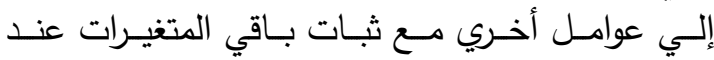
متوسطاتها الحسابية.

\section{3- تطور الإنتاجية الفذانية لنخيل البلح}

بدراسة تطور إنتاجية نخيل البلح بححافظة الواديل

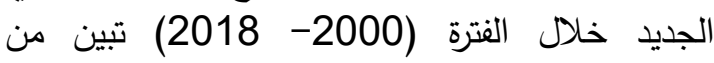
الجدول رقم (1) أن الحد الأدنى لإنتاجية النخلة قد بلغ

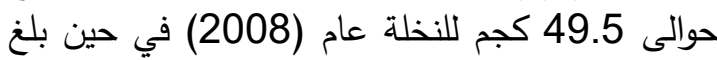

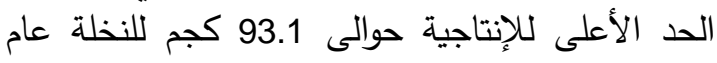

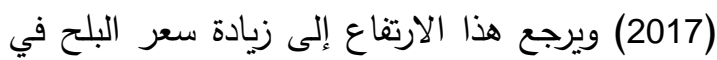

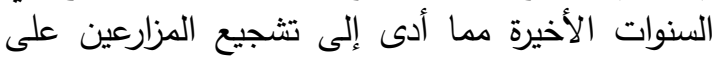

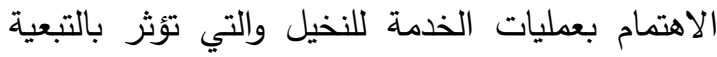

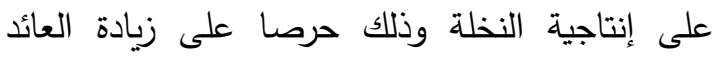
المادي، وبتقدير الاتجاه الزمنى العـام لتطور الإنتاجية
يتطلب الاهتمام بأثجار النخيل واختيار أصناف ذات صفات عالية الجودة والعمل علي نشرها بالمحافظة) (. ويتضـح من الجدول رقم (1) أن متوسط المساحة

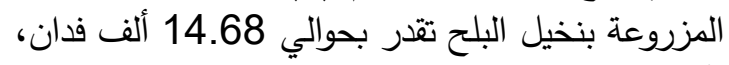
وأن متوسط إنتاجية النخلة بمحافظة الوادي الجديد يقدر

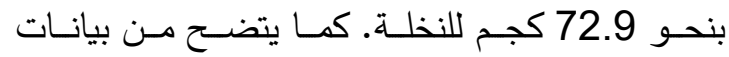
الجدول أيضاً أن عدد الأشجار الإناث المثمرة بمحافظة لإنة

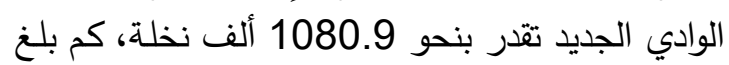
متوسط الإنتاج نحو 78.9 ألف طن كمتوسط للفترة المشار إليها. وبدراسـة تطـور المســاحة المزروعـة بنخيـل الـبلح

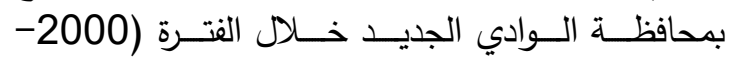

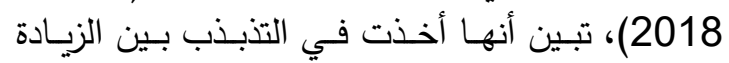

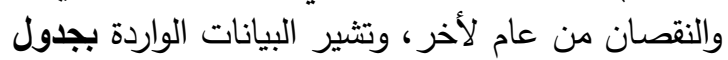

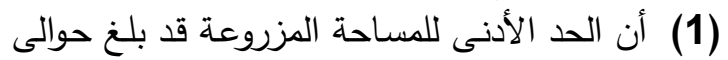

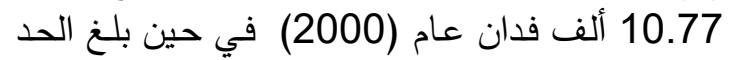

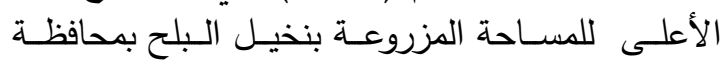
الوادي الجديد خـلال نفس الفترة حوالى 23.79 ألف الف الف

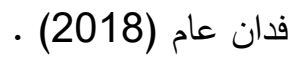
وبتقدير الاتجاه العام لتطور مساحة نخيل البلح في محافظة الوادي الجديد خلال الفترة (2000- 2018)

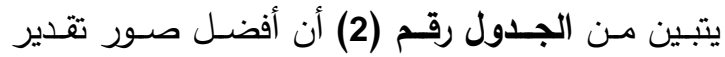

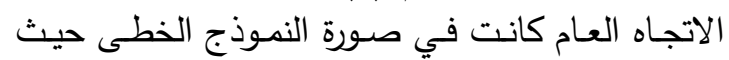

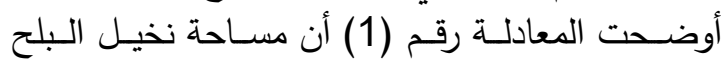

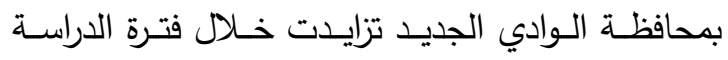

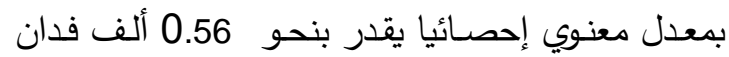

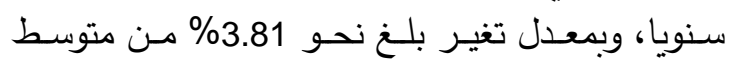

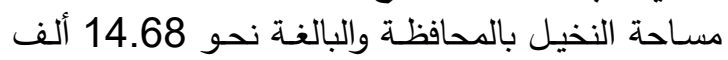

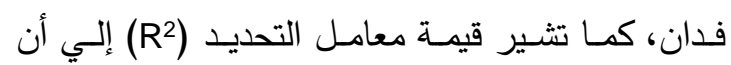

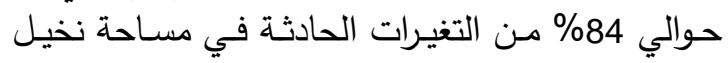

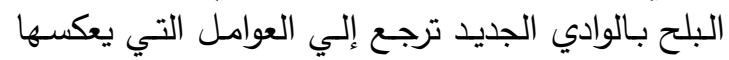

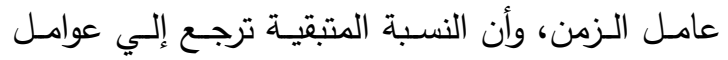

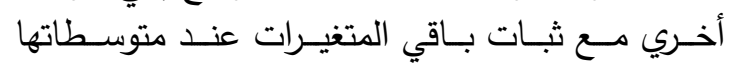

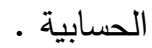




$$
\text { إلهام أحمد - السنتريسى - عبد المقصود }
$$

جدول 1 ـ تطور مساحة وأعداد الإناث المثمرة والإنتاجية والإنتاج من نخيل البلح بمحافظة الوادي الجديد خلال الفترة (2000- 2018)

\begin{tabular}{|c|c|c|c|c|}
\hline \multicolumn{4}{|c|}{ الوادي الجديد } & \multirow{2}{*}{ لان / ل السنة } \\
\hline ألف طن & كجم| الإنتاجية نخلة & الإنفاث المثمرة & ألف فداحة & \\
\hline 51.98 & 69.1 & 752.47 & 10.77 & 2000 \\
\hline 57.02 & 72.5 & 786.39 & 11.36 & 2001 \\
\hline 65.72 & 80.8 & 812.92 & 11.82 & 2002 \\
\hline 72.22 & 79.9 & 903.49 & 11.93 & 2003 \\
\hline 70.29 & 79.9 & 879.28 & 12.46 & 2004 \\
\hline 72.42 & 79.8 & 907.69 & 12.74 & 2005 \\
\hline 65.95 & 73.6 & 895.93 & 12.34 & 2006 \\
\hline 45.23 & 50.0 & 904.13 & 12.03 & 2007 \\
\hline 46.04 & 49.5 & 931.02 & 12.57 & 2008 \\
\hline 49.38 & 50.1 & 985.81 & 13.50 & 2009 \\
\hline 51.60 & 53.2 & 969.62 & 13.88 & 2010 \\
\hline 85.75 & 82.0 & 1046.20 & 14.37 & 2011 \\
\hline 94.80 & 81.8 & 1159.37 & 16.12 & 2012 \\
\hline 83.09 & 72.0 & 1153.44 & 16.07 & 2013 \\
\hline 100.31 & 81.7 & 1227.42 & 17.54 & 2014 \\
\hline 103.12 & 81.7 & 1262.48 & 18.48 & 2015 \\
\hline 112.53 & 84.2 & 1336.32 & 18.55 & 2016 \\
\hline 131.34 & 93.1 & 1410.15 & 18.62 & 2017 \\
\hline 140.74 & 63.6 & 2213.07 & 23.79 & 2018 \\
\hline 78.92 & 73.0 & 1080.91 & 14.68 & المتوسط \\
\hline
\end{tabular}

المصدر: وزارة الزراعة واستصلاح الأراضي، قطاع الشئون الاقتصادية، نشرة الإحصاءات الزراعية، أعداد متفرقة (2000-2018). 
1709 تقييم اقتصادي لصناعة تعبئة وتغليف البلح بمحافظة الوادي الجديد (دراسة حالة) جدول 2. معادلات الاتجاه الزمني العام لتطور الدساحة والإنتاج والإنتاجية وأعداد الإناث الهثمرة من النخيل بمحافظة الوادي الجديد خلات الفترة (2000- 2018)

\begin{tabular}{|c|c|c|c|c|c|}
\hline معدل التغير & $\mathbf{F}$ & $\mathbf{R}^{2}$ & صياغة المعادلة & البيان & p \\
\hline$\% 3.81$ & *91.7 & 0.84 & $\begin{aligned} Y i= & 9.11+.56 \mathrm{Xi} \\
& (13.7) \quad(9.57)\end{aligned}$ & المساحة & 1 \\
\hline$\% 5.06$ & $* 27.78$ & 0.62 & $\begin{array}{r}Y i=39.056+3.99 X i \\
(4.52) \quad(5.27)\end{array}$ & الإنتاج & 2 \\
\hline$\% 0.71$ & 0.47 & 0.03 & $\begin{array}{cc}Y i= & 68.7+0.39 X i \\
(10.72) & (0.69)\end{array}$ & الإنتاجية & 3 \\
\hline$\% 4.51$ & $* 35.68$ & 0.68 & $\begin{array}{r}Y i=593.36+48.75 \times i \\
(6.37)\end{array}$ & أعداد الإناث & 4 \\
\hline
\end{tabular}

المصدر: حسبت من البيانات الواردة بجدول (1).

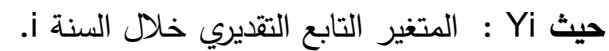

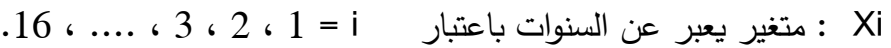

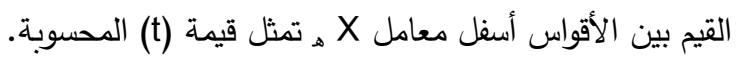

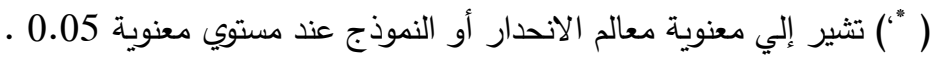

الفترة زيادة معنوية إحصائيا قدرها 48.75 كجم سنويا، وأنها قد أخذت اتجاهاً عاماً متزايداً ومعنوي إحصائياً

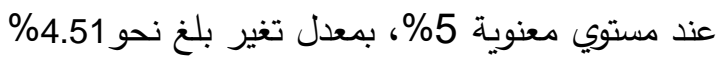
من متوسط أعداد الإناث المثمرة للنخيل بالمحافظة

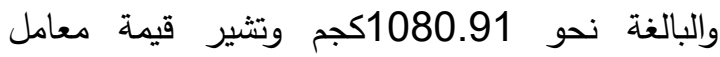

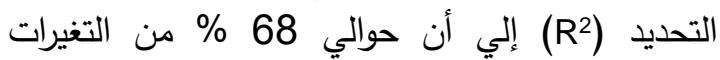
الحادثة في أعداد الإناث المثمرة للنخيل ترجع إلي الئي

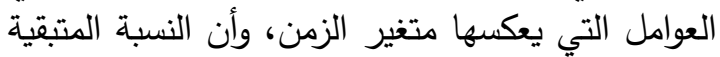

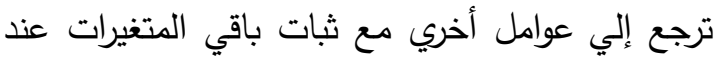

$$
\text { متوسطاتها الحسابية. }
$$

\section{وصف منطقة الدراسة}

تضم محافظة الوادي الجديد خمسـة مراكز إداريـة

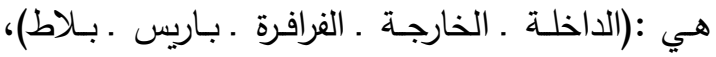

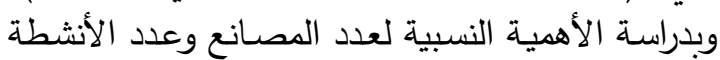
الاقتصادية بمختلف المراكز الإدارية، تبين من الجدول

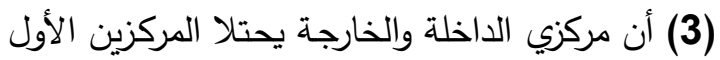
والثاني ممثلة نحو 38.53\%، 36.7\% علي التركي الترتيب من إجمالي عدد المصانع في محافظة الوادي الجديد عاليد
لنخيل البلح بمحافظة الوادي الجديد خلال الفترة السابقة تبين من الجدول رقم (2) والمعادلة رقم (3) عدم الجمالية

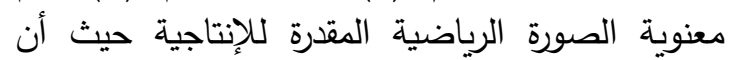
البيانات تدور حول متوسطها الحسابي.

4- تطور أعداد الإناث المثمرة لنخيل البلح

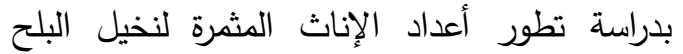
بمحافظة الوادي الجديد خلال الفترة (2000- 2018) تبين من الجدول رقم (1) أن الحد الأدنى لأعداد

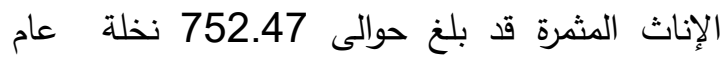
(2000) في حين بلغ الحد الأعلى لأعداد الإناث

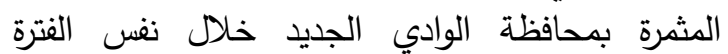
السابقة حوالى 2213.07 كجم للنخلة عام (2018)، وبمتوسط خلال الفترة بلغ حوالى 1081 ألف نخلة الفالف

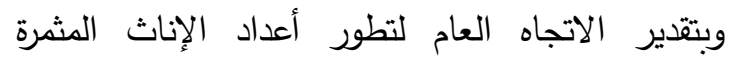

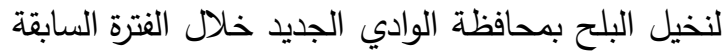

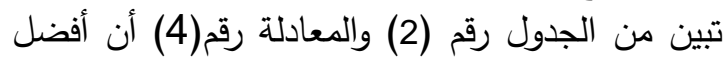

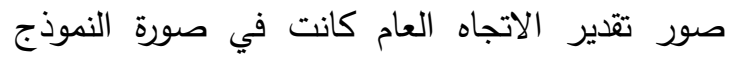
الخطى حيث تزايد عدد الأشجار المثمرة خلال تلاه 
الآلات، تكــاليف إهــلاكك السـيارات، تكــاليف إهــلاك الأثـاث)، والتـي تراوحـت مـا بـين. (0.47 - 4.08) مليون جنية ، كحد أدنى وحد أعلى على والتى الترتيب من إجمالى التكاليف الثابتة.

ثالثا: التكاليف التشغيلية المباشرة للمنشآت

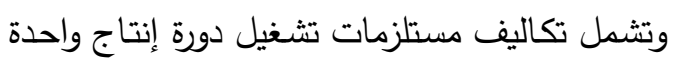
ومـن عناصـرها (تكـاليف المـواد الخـام، أجـور العمالـة

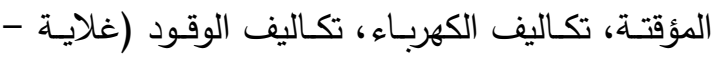

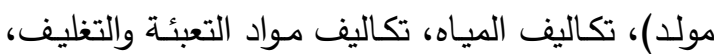
تكاليف الصيانة، تكاليف التبخير)، والتي تراوحت مـا بين (6.05 - 98.52) مليون جنية .

التكاليف التشغيلية الغير مباشرة للمنشآت

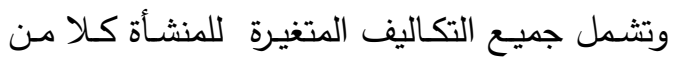

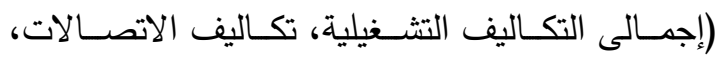

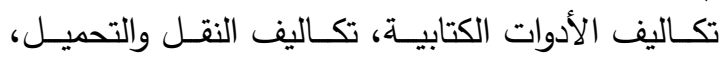
تكاليف الضرائب، تكاليف نثريـة)، والتي تراوحت ما بين

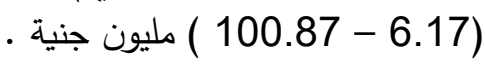

خامسا: التكاليف الكلية للمنشآت هي مجموع التكاليف الثابتة والتكاليف المتغيرة التي تتفقها الوحدة الإنتاجية في سبيل الحصول على إنتاج

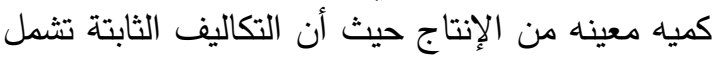
كافة أوجه التكاليف الخاصة بعناصر الإنتاج الثابتة

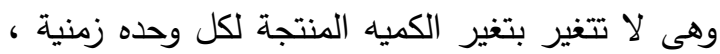
أي أنها تلك التكلفة التي تتحملها الوحدة الإنتاجية بصرف النظر عن كمية الإنتاج التي تتتجها، أما التكاليف المتغيرة فهي تلك التكلفة التي تتحملها المنشأة لإنتاج منتج ما والتي تتغير مع تغير كمية الإنتاج، حيث تؤدى زيادة استخدام الموارد إلى زيادة كمية فئية الإنتاج. ويمكن وضع هذه التكاليف في الصورة التالية:

$$
\text { التكاليف الكلية = التكاليف المتغيرة + التكاليف الثابتة }
$$

حيث تراوحت التكاليف الكلية بين (6.77- 104.94) مليون جنية.

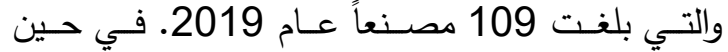
احتلت مراكز الفرافرة، باريس، بلاط المراكز التالية علي

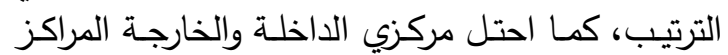

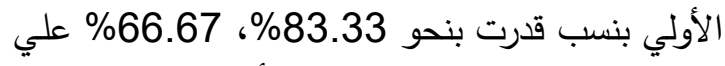
الترتيب، وذلك من إجمالي عدد الأنشطة في محافظة

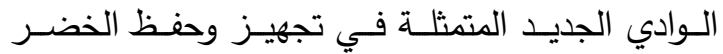

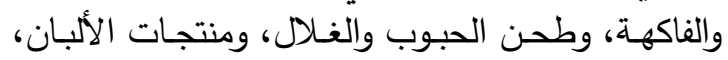

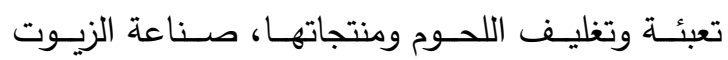
والدهون، صـناعة الأعـلاف الديوانيـة المعدة، والتـي

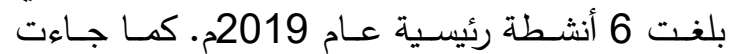
مراكز الفرافرة، باريس، بلاط في المراتب التالية علي الترتيب. - مركز

وعلي ذلك فقد تم اختيار أعلى مركزين بمحافظة الوادي الجديد وهما مركزي (الخارجة والداخلة) لتمثل

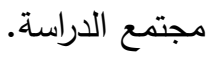
أهم مكونات بنود التكاليف والإيرادات وقد تم دراسة كلا من جانبي التكاليف والإيرادات

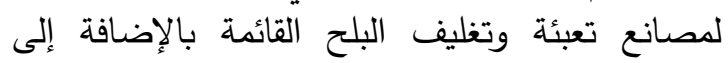
الجدوى المالية والاقتصادية لهذه الدصانع وفقا لما يلى: أولا: التكاليف الاستثمارية للمنشأة

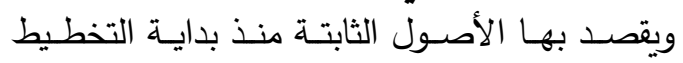

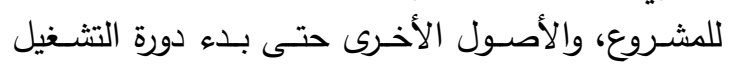

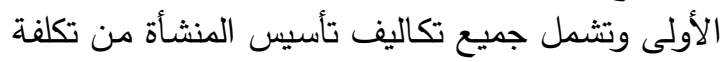

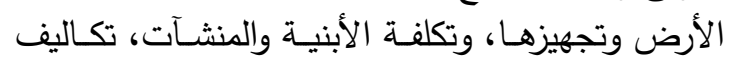

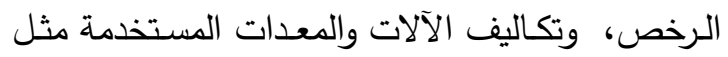

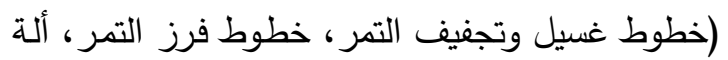

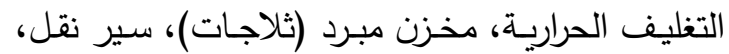

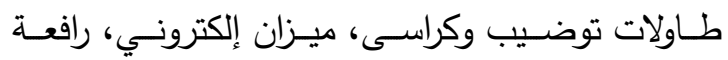

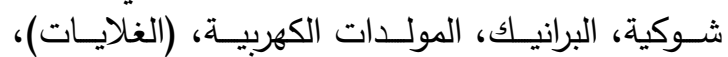
وتكاليف الأثاث، وتكاليف السيارات والجرارات التوات ـ والتي

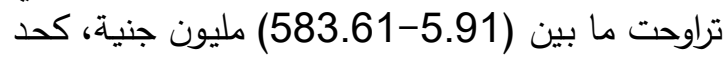

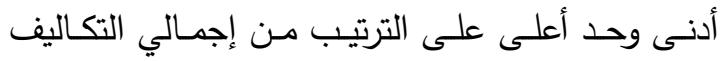

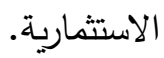
ثانيا: التكاليف الثابتة للمنشآت

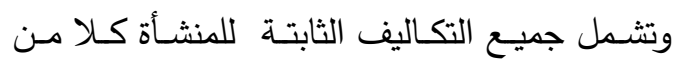

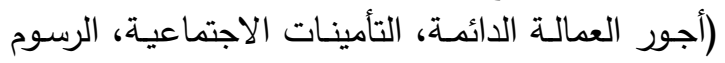

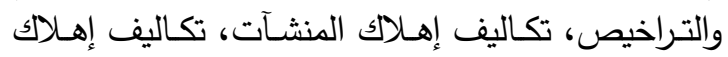


1711

تقييم اقتصادي لصناعة تعبئة وتغليف البلح بمحافظة الوادي الجديد (دراسة حالة)

جدول 3. الأهمية النسبية لعدد المصانع والأنشطة موزعة علي المراكز الإدارية بمحافظة الوادي الجديد خلال عام

2019

\begin{tabular}{|c|c|c|c|c|}
\hline الأهمية النسبية لعدد المصانع & عدد المصاتع & $\begin{array}{c}\text { الأهمية النسبية لعدد الأنثطة } \\
\text { (\%) }\end{array}$ & عدد الأنثطة & المراكز \\
\hline 36.70 & 40 & 66.67 & 4 & الخارجة \\
\hline 38.53 & 42 & 83.33 & 5 & الداخلة \\
\hline 13.76 & 15 & 66.67 & 4 & الفرافرة \\
\hline 5.50 & 6 & 50.00 & 3 & باريس \\
\hline 5.50 & 6 & 16.67 & 1 & بلاط \\
\hline 100.00 & 109 & - & 6 & الإجمالي \\
\hline
\end{tabular}

تم حساب الأهمية النسبية لعدد الأنشطة لكل مركز بالنسبة إلى إجمالي عدد الأنشطة بالمحافظة والبالغ نحو (6) أنشطة المصدر: جمعت وحسبت من بيانات الجهاز المركزي، للتعبئة العامة والإحصاء بيانات غير منشورة.(2019).

جدول 4 ـ التكاليف الاستثمارية لمصانع البلح بمحافظة الوادي الجديد. بالمليون جنية)

\begin{tabular}{|c|c|c|c|c|c|c|c|c|c|}
\hline \multicolumn{9}{|c|}{ التكاليف الاستثماربة ( ما قبل الإنتاج ) } & \multirow[b]{2}{*}{ p } \\
\hline الإستاليفي & السيارات & تالكاليف & والكاليف & تكاليف & تكاليف & الأرض أو أون & سأرضر & مالأرضاحة & \\
\hline 583.61 & 3.00 & 0.650 & 5.47 & 0.047 & 14.44 & 560.00 & 0.002 & 280000 & 1 \\
\hline 23.32 & 1.65 & 0.600 & 4.31 & 0.039 & 8.72 & 8.00 & 0.002 & 4000 & 2 \\
\hline 12.79 & 1.50 & 0.300 & 3.16 & 0.03 & 3.00 & 4.80 & 0.002 & 2400 & 3 \\
\hline 12.41 & 1.21 & 0.466 & 3.94 & 0.018 & 3.38 & 3.40 & 0.002 & 1700 & 4 \\
\hline 12.03 & 0.92 & 0.632 & 4.72 & 0.005 & 3.75 & 2.00 & 0.002 & 1000 & 5 \\
\hline 11.16 & 1.00 & 0.450 & 4.50 & 0.007 & 3.20 & 2.00 & 0.002 & 1000 & 6 \\
\hline 187.00 & 1.22 & 0.690 & 7.20 & 0.009 & 6.27 & 171.62 & 0.002 & 85811 & 7 \\
\hline 9.56 & 0.85 & 0.200 & 3.70 & 0.011 & 2.60 & 2.20 & 0.002 & 1100 & 8 \\
\hline 7.31 & 0.90 & 0.050 & 1.75 & 0.01 & 2.60 & 2.00 & 0.002 & 1000 & 9 \\
\hline 8.88 & 0.63 & 0.220 & 2.82 & 0.009 & 3.00 & 2.20 & 0.002 & 1100 & 10 \\
\hline 13.02 & 0.92 & 0.513 & 5.08 & 0.005 & 3.50 & 3.00 & 0.002 & 1500 & 11 \\
\hline 7.96 & 0.75 & 0.100 & 1.50 & 0.011 & 2.40 & 3.20 & 0.002 & 1600 & 12 \\
\hline 4.86 & 0.60 & 0.050 & 0.75 & 0.023 & 1.70 & 1.74 & 0.002 & 870 & 13 \\
\hline 7.24 & 1.05 & 0.065 & 1.00 & 0.012 & 2.12 & 3.00 & 0.002 & 1500 & 14 \\
\hline 13.80 & 0.90 & 0.046 & 0.85 & 0.005 & 2.00 & 10.00 & 0.002 & 5000 & 15 \\
\hline 5.91 & 0.67 & 0.050 & 0.93 & 0.006 & 1.76 & 2.50 & 0.002 & 1250 & 16 \\
\hline
\end{tabular}

المصدر: استمارة الاستبيان المعدة لبنود التكاليف والإيرادات والتي تم استيفائها عن طريق المقابلة الثخصية لأصحاب المصانع والمديرين وفقا لبيانات عام 2019. 


$$
\text { إلهام أحمد - السنتريسى - عبد المقصود }
$$

(بالمليون جنية)

جدول 4. التكاليف الثابتة لمصانع البلح بمحافظة الوادي الجديد.

\begin{tabular}{|c|c|c|c|c|c|c|c|c|c|}
\hline \multicolumn{9}{|c|}{ التكاليف الثابتة } & \multirow{4}{*}{ r } \\
\hline \multirow{3}{*}{ التكاليف } & \multirow{3}{*}{ إلكاليف } & تكاليف & تكاليف & & & \multirow{3}{*}{ والتراخيص } & \multirow{3}{*}{ الاجتماعية } & \multirow{3}{*}{ الألعمالة } & \\
\hline & & إئهلاك & إهلاك & إنهلاك & إهلاك & & & & \\
\hline & & $16.7 \%$ & $20 \%$ & $6.7 \%$ & $4 \%$ & & & & \\
\hline 4.08 & 1.65 & 0.11 & 0.60 & 0.36 & 0.58 & 0.035 & 0.33 & 2.06 & 1 \\
\hline 2.67 & 1.07 & 0.10 & 0.33 & 0.29 & 0.35 & 0.040 & 0.26 & 1.30 & 2 \\
\hline 1.27 & 0.68 & 0.05 & 0.30 & 0.21 & 0.12 & 0.033 & 0.20 & 0.36 & 3 \\
\hline 1.50 & 0.72 & 0.08 & 0.24 & 0.26 & 0.14 & 0.045 & 0.23 & 0.51 & 4 \\
\hline 1.53 & 0.75 & 0.11 & 0.18 & 0.31 & 0.15 & 0.030 & 0.27 & 0.48 & 5 \\
\hline 1.31 & 0.70 & 0.08 & 0.20 & 0.30 & 0.13 & 0.040 & 0.24 & 0.33 & 6 \\
\hline 1.51 & 1.09 & 0.12 & 0.24 & 0.48 & 0.25 & 0.038 & 0.21 & 0.18 & 7 \\
\hline 1.03 & 0.55 & 0.03 & 0.17 & 0.25 & 0.10 & 0.055 & 0.23 & 0.19 & 8 \\
\hline 0.90 & 0.41 & 0.01 & 0.18 & 0.12 & 0.10 & 0.035 & 0.10 & 0.36 & 9 \\
\hline 1.21 & 0.47 & 0.04 & 0.13 & 0.19 & 0.12 & 0.040 & 0.20 & 0.50 & 10 \\
\hline 1.50 & 0.75 & 0.09 & 0.18 & 0.34 & 0.14 & 0.038 & 0.24 & 0.48 & 11 \\
\hline 0.78 & 0.36 & 0.02 & 0.15 & 0.10 & 0.10 & 0.020 & 0.10 & 0.30 & 12 \\
\hline 0.47 & 0.25 & 0.01 & 0.12 & 0.05 & 0.07 & 0.030 & 0.05 & 0.14 & 13 \\
\hline 0.74 & 0.37 & 0.01 & 0.21 & 0.07 & 0.08 & 0.041 & 0.09 & 0.24 & 14 \\
\hline 0.56 & 0.32 & 0.01 & 0.18 & 0.06 & 0.08 & 0.050 & 0.09 & 0.10 & 15 \\
\hline 0.61 & 0.27 & 0.01 & 0.13 & 0.06 & 0.07 & 0.025 & 0.06 & 0.25 & 16 \\
\hline
\end{tabular}

الدصدر: استمارة الاستبيان المعدة لبنود التكاليف والإيرادات والتي تم استيفائها عن طريق الدقابلة الثخصية لأصحاب

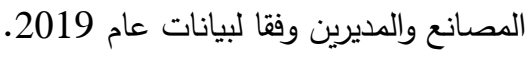


1713

تقييم اقتصادي لصناعة تعبئة وتغليف البلح بمحافظة الوادي الجديد (دراسة حالة)

(بالمليون جنية)

جدول 5. التكاليف التشغيلية لمصانع البلح بمحافظة الوادي الجديد.

\begin{tabular}{|c|c|c|c|c|c|c|c|c|c|}
\hline التكاليف & تكاليف التبخير & تكاليف & تكاليف & تكاليف & تكاليف & تكاليف & أجور العوالة & الكاليف & p \\
\hline 98.52 & 0.60 & 0.400 & 15.00 & 0.100 & 0.116 & 0.24 & 1.17 & 80.894 & 1 \\
\hline 70.01 & 0.53 & 0.297 & 1.00 & 0.088 & 0.100 & 0.21 & 0.86 & 66.929 & 2 \\
\hline 56.43 & 0.45 & 0.194 & 0.90 & 0.075 & 0.000 & 0.18 & 0.54 & 54.085 & 3 \\
\hline 42.60 & 0.34 & 0.100 & 0.67 & 0.065 & 0.000 & 0.14 & 0.81 & 40.487 & 4 \\
\hline 31.42 & 0.23 & 0.015 & 0.44 & 0.054 & 0.044 & 0.09 & 1.08 & 29.478 & 5 \\
\hline 27.59 & 0.21 & 0.024 & 0.42 & 0.030 & 0.041 & 0.17 & 1.05 & 25.635 & 6 \\
\hline 26.23 & 0.20 & 0.033 & 0.40 & 0.006 & 0.039 & 0.25 & 1.03 & 24.267 & 7 \\
\hline 23.85 & 0.18 & 0.050 & 0.25 & 0.024 & 0.000 & 0.12 & 0.81 & 22.415 & 8 \\
\hline 18.79 & 0.15 & 0.072 & 0.15 & 0.022 & 0.000 & 0.06 & 0.45 & 17.89 & 9 \\
\hline 20.13 & 0.15 & 0.042 & 0.30 & 0.024 & 0.020 & 0.12 & 0.90 & 18.57 & 10 \\
\hline 20.25 & 0.15 & 0.010 & 0.29 & 0.036 & 0.029 & 0.06 & 0.90 & 18.776 & 11 \\
\hline 14.57 & 0.11 & 0.035 & 0.30 & 0.015 & 0.050 & 0.09 & 0.53 & 13.436 & 12 \\
\hline 10.36 & 0.08 & 0.022 & 0.35 & 0.006 & 0.000 & 0.10 & 0.31 & 9.4924 & 13 \\
\hline 9.97 & 0.08 & 0.030 & 0.40 & 0.006 & 0.000 & 0.09 & 0.45 & 8.9313 & 14 \\
\hline 8.18 & 0.06 & 0.035 & 0.25 & 0.005 & 0.015 & 0.07 & 0.54 & 7.201 & 15 \\
\hline 6.05 & 0.05 & 0.033 & 0.20 & 0.006 & 0.000 & 0.07 & 0.30 & 5.3985 & 16 \\
\hline
\end{tabular}

المصدر: استمارة الاستبيان المعدة لبنود التكاليف والإيرادات والتي تم استيفائها عن طريق المقابلة الثخصية لأصحاب

المصانع والمديرين وفقا لبيانات عام الصنان العدة لبنود 2019 


$$
\text { إلهام أحمد - السنتريسى - عبد المقصود }
$$

(بالمليون جنية)

جدول 6. إجمالى التكاليف المتغيرة بمحافظة الوادي الجديد.

\begin{tabular}{|c|c|c|c|c|c|c|c|}
\hline إجمالى التكاليف & تثاليف & الضرائيف & تكاليف النقل & الكالكاليت & |الاتصالات & التكاليفي & e \\
\hline 100.87 & 0.020 & 0.487 & 1.80 & 0.039 & 0.003 & 98.52 & 1 \\
\hline 71.60 & 0.015 & 0.345 & 1.20 & 0.032 & 0.008 & 70.01 & 2 \\
\hline 57.10 & 0.010 & 0.028 & 0.60 & 0.025 & 0.012 & 56.43 & 3 \\
\hline 43.25 & 0.010 & 0.145 & 0.47 & 0.020 & 0.007 & 42.60 & 4 \\
\hline 31.85 & 0.007 & 0.068 & 0.34 & 0.018 & 0.002 & 31.42 & 5 \\
\hline 27.96 & 0.009 & 0.074 & 0.27 & 0.014 & 0.003 & 27.59 & 6 \\
\hline 26.53 & 0.011 & 0.073 & 0.20 & 0.009 & 0.004 & 26.23 & 7 \\
\hline 24.15 & 0.007 & 0.057 & 0.23 & 0.010 & 0.008 & 23.85 & 8 \\
\hline 19.09 & 0.003 & 0.072 & 0.20 & 0.012 & 0.012 & 18.79 & 9 \\
\hline 20.40 & 0.005 & 0.051 & 0.21 & 0.009 & 0.004 & 20.13 & 10 \\
\hline 20.55 & 0.005 & 0.033 & 0.25 & 0.012 & 0.001 & 20.25 & 11 \\
\hline 14.81 & 0.005 & 0.045 & 0.18 & 0.008 & 0.003 & 14.57 & 12 \\
\hline 10.50 & 0.006 & 0.023 & 0.11 & 0.005 & 0.002 & 10.36 & 13 \\
\hline 10.12 & 0.003 & 0.019 & 0.12 & 0.006 & 0.002 & 9.97 & 14 \\
\hline 8.31 & 0.002 & 0.022 & 0.10 & 0.005 & 0.005 & 8.18 & 15 \\
\hline 6.17 & 0.002 & 0.019 & 0.08 & 0.006 & 0.006 & 6.05 & 16 \\
\hline
\end{tabular}

المصدر: استمارة الاستبيان المعدة لبنود التكاليف والإيرادات والتني تم استيفائها عن طريق الدقابلة الشخصية لأصحاب المصانع والمديرين وفقا لبيانات عام 2019. 
(بالمليون جنية) جدول 7. - الإجمالي العام للتكاليف

\begin{tabular}{|c|c|c|c|}
\hline الإجمالي العام للتكاليف & إجمالى التكاليف المتغيرة & إجمالى التكاليف الثابتة & p \\
\hline 58.37 & 57.10 & 1.27 & 3 \\
\hline 44.76 & 43.25 & 1.50 & 4 \\
\hline 33.38 & 31.85 & 1.53 & 5 \\
\hline 29.27 & 27.96 & 1.31 & 6 \\
\hline 28.04 & 26.53 & 1.51 & 7 \\
\hline 25.18 & 24.15 & 1.03 & 8 \\
\hline 19.99 & 19.09 & 0.90 & 9 \\
\hline 21.62 & 20.40 & 1.21 & 10 \\
\hline 22.06 & 20.55 & 1.50 & 11 \\
\hline 15.59 & 14.81 & 0.78 & 12 \\
\hline 10.97 & 10.50 & 0.47 & 13 \\
\hline 10.86 & 10.12 & 0.74 & 14 \\
\hline 8.87 & 8.31 & 0.56 & 15 \\
\hline 6.77 & 6.17 & 0.61 & 16 \\
\hline
\end{tabular}

المصدر: جمعت وحسبت من جداول التكاليف رقم (7)، ورقم (8): باستخدام برنامج Excel .

التقييم الاقتصادي والمالي لصناعة تعيئة وتظليف البلح بحافظة الوادي الجديد

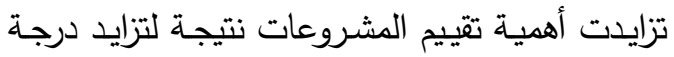

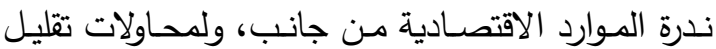

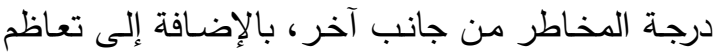

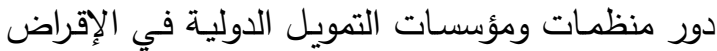

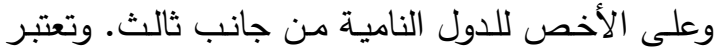

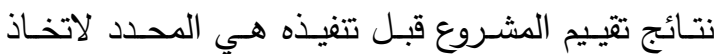

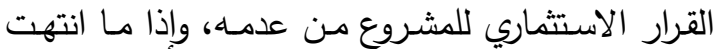

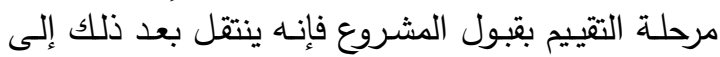
مرحلة التنفيذ، هذا وقد تجرى عملية تقييم المشروع بعد التئي

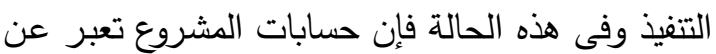

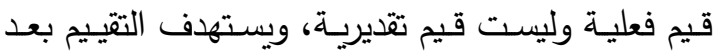

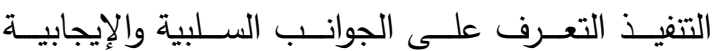
للاستفادة منها في تحسين أداء المشروع وتتعدد طرق الإن الإني

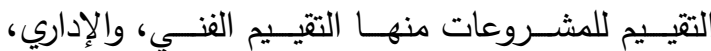

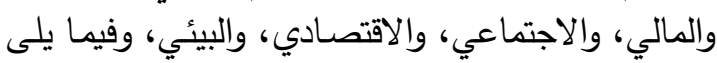
عرض موجز للتقييم والمالي والاجتماعي للمشروعات.
سادسا :الإيرادات من المنثآت

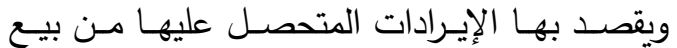

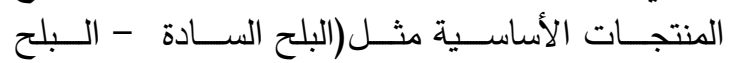
بالسوداني - البلح باللوز - البلح بالثيكولاتة) وكذلك الكان الكان

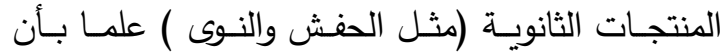
الحفش هو البلح التالف، ويمكن تقديرها كالتالي:

$$
\text { الإيراد/ت = إجمالى الإيراد/ت للمنتج الأساسي + لإسيات }
$$
إجمالمى الإيرادات للمنتج الثانوي لإني

وبالنسبة للربح الصافي فيتم حسابه كالتالي:

$$
\text { الربح الصافي = إجنمالى الإيرادات الكلية - إجمالى }
$$

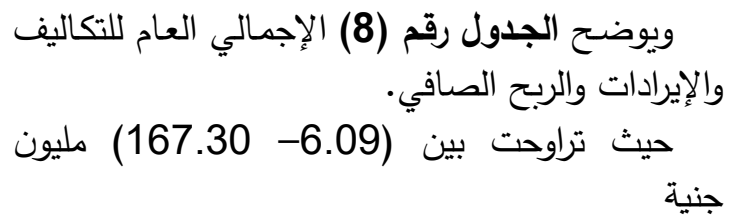


إلهام أحمد - السنتريسى - عبد المقصود

(بالمليون جنية)

جدول 8. الربح الصافي لمصانع البلح

\begin{tabular}{|c|c|c|c|c|c|}
\hline الربح الصافي & إجمالى الإيرادات & إجمالى إيرادات & إجمالى إيرادات & إجمالى التكاليف & b \\
\hline 167.30 & 272.24 & 2.04 & 270.20 & 104.94 & 1 \\
\hline 114.66 & 188.94 & 1.79 & 187.15 & 74.27 & 2 \\
\hline 69.16 & 127.53 & 1.53 & 126.00 & 58.37 & 3 \\
\hline 48.14 & 92.90 & 1.15 & 91.75 & 44.76 & 4 \\
\hline 22.46 & 55.84 & 0.74 & 55.10 & 33.38 & 5 \\
\hline 24.49 & 53.75 & 0.73 & 53.03 & 29.27 & 6 \\
\hline 24.24 & 52.28 & 0.69 & 51.59 & 28.04 & 7 \\
\hline 19.09 & 44.27 & 0.60 & 43.68 & 25.18 & 8 \\
\hline 23.02 & 43.01 & 0.51 & 42.50 & 19.99 & 9 \\
\hline 16.34 & 37.96 & 0.51 & 37.45 & 21.62 & 10 \\
\hline 10.97 & 33.03 & 0.51 & 32.52 & 22.06 & 11 \\
\hline 14.80 & 30.38 & 0.38 & 30.00 & 15.59 & 12 \\
\hline 7.22 & 18.20 & 0.26 & 17.94 & 10.97 & 13 \\
\hline 6.09 & 16.96 & 0.26 & 16.70 & 10.86 & 14 \\
\hline 7.39 & 16.25 & 0.20 & 16.05 & 8.87 & 15 \\
\hline 6.13 & 12.90 & 0.15 & 12.75 & 6.77 & 16 \\
\hline
\end{tabular}

المصدر: جمعت وحسبت من جداول التكاليف رقم (7)، ورقم (9) و رقم (10) باستخدام برنامج Excel

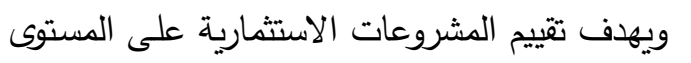

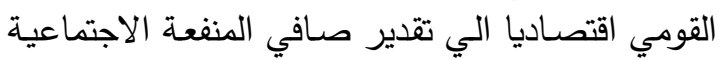

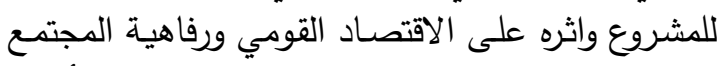

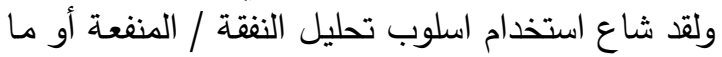

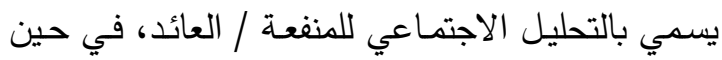

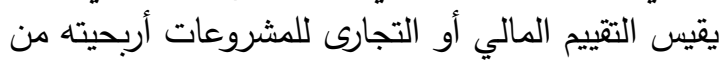

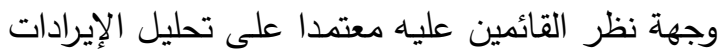

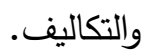

معايير التقييم للمشروعات العاملة

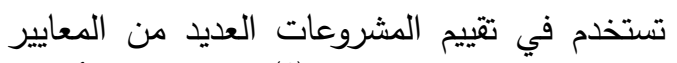
والمقاييس المألية والاقتصادية(1) ولعل من المئية أهمها،

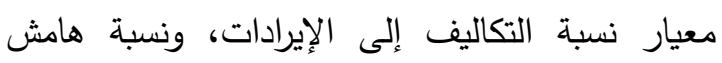

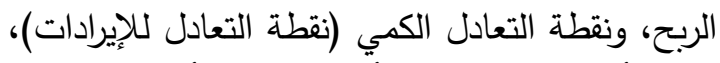

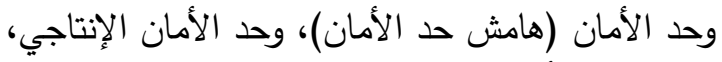

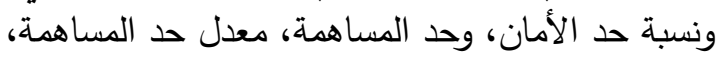

لاببـد ان نوضـح بدايـة ان عمليـة تقييم المشروعات

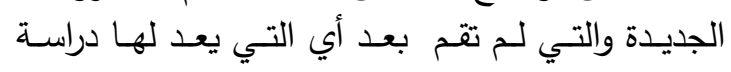

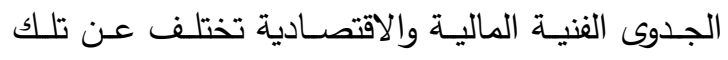

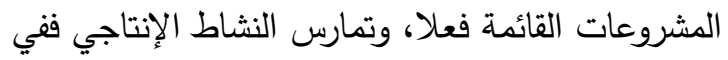

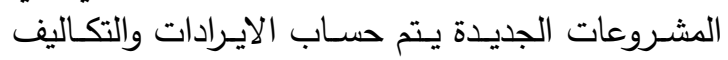

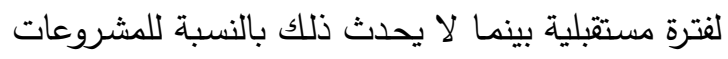

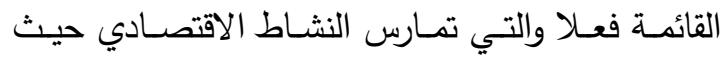

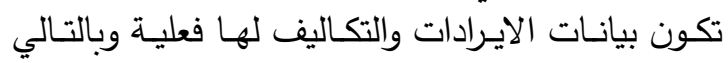

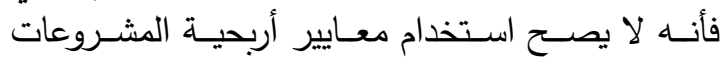

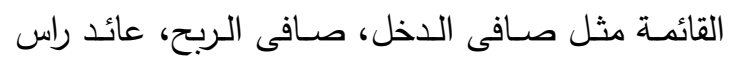

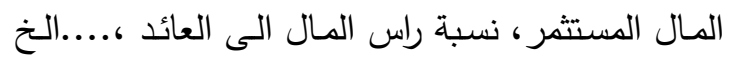

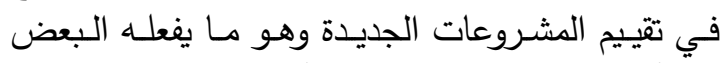

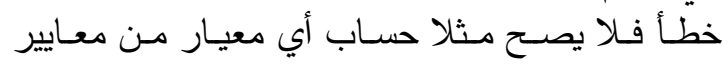

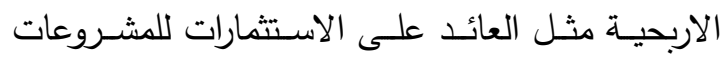

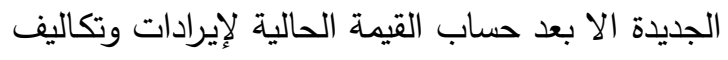

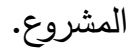


الاستثمارية بالإشارة الي كونها مشاريع زراعية صناعية

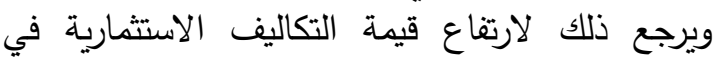
المرحلة الأولى من عمر المشروع · لإنة

\section{( 3 ـ العائد على الجنيه المستثمر} ويحسب بقسمة إجمالى الإيرادات على إلجمالى الجماتى

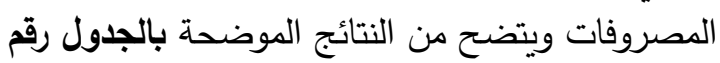

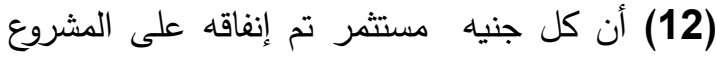

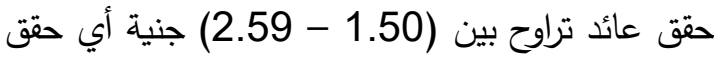

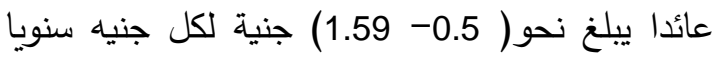
مما يؤكد ارتفاع ربحية هذه المشاريع.

معايير المخاطرة لكفاءة الاستثمار

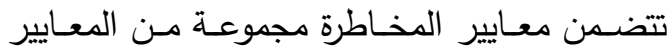

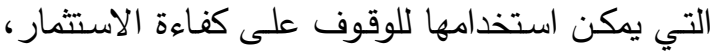

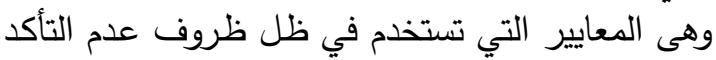
وسوف نتناول هذه المعايير بإيجاز فيما يلى:

1) معيار نقطة التعادل للكمية

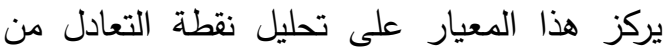
خلال دراسة العلاقات بين الإيرادات والتكاليف والأرباح وعند مستويات مختلفة من الإنتاج والمبيعات. إن تحليل نقطة التعادل منهج لتخطيط الربحية

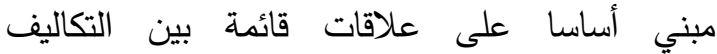

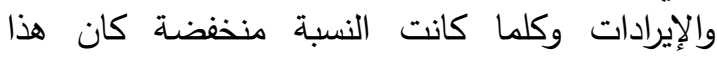

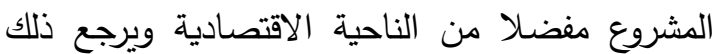

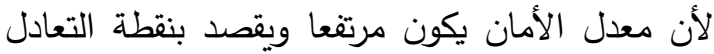
النقطة التي يتحقق عندها التساوي بين الإيرادات الكلية لإنية والتكاليف الكلية لناتج معين أي النقطة التي لا لآكون فيها أرباح ولا خسائر . وتحسب رياضيا من المعادلة التالية:

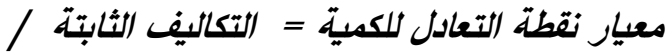 (الإيرادات الكلية ـ التكاليف الدتغيةر)}

وتوضح نتائج هذا المعيار بالجدول رقم (9) أن البعان

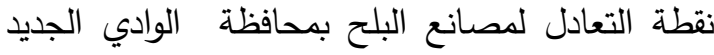

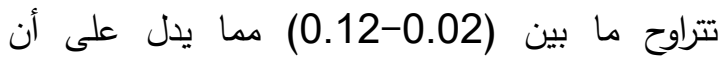

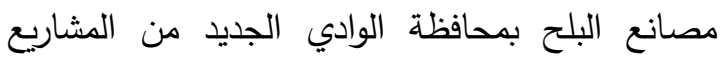

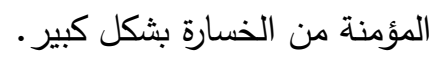

والعائد على الجنية وتساعد هذه المعايير في عملية اتخاذ القرارات وإعطاء فكرة عن المنفعة الاقتصادية فئسية للمشاريع على المستوى القومي.

التقييم المالي لصناعة تعبئة وتظليف البلح بححافظة

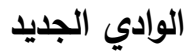
يستهذف إجراء التقييم المسالي للمشروعات توفير المبات

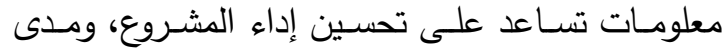

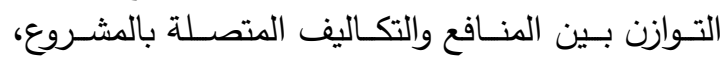
فهناك العديد من الأساليب التي يمكن الاعتماد عليها في تقييم المشروعات لتقدير العائد الاقتصادي والمالي.

1ـ نسبة المنافع للتكاليف (دليل الربحية)

\section{Cost/Benefit}

ويعتبر المشروع مقبول اقتصاديا إذا كانت النتيجة

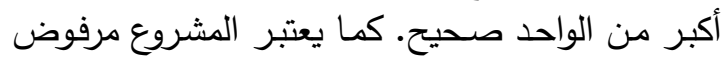

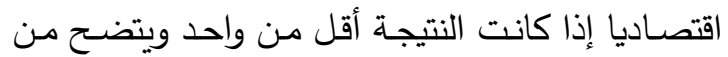
الجدول رقم (9) أن نسبة النيجة

العائد للتكاليف لمشروعات تعبئة وتنغليف البلح قد

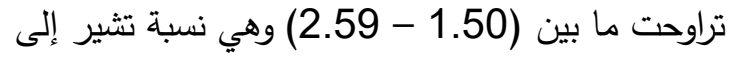
جدوى الاستثار في هذا المشروع وفقا لهذا المعيار

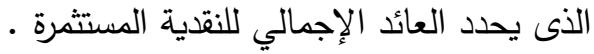

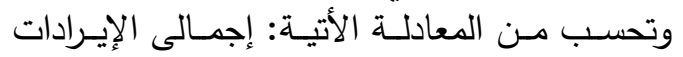
للمشروع مقسوما على إجمالى التكاليف لهذا المشروع. 2ـ فترة استرداد أموال المشروع من المعايير التي تمكن من الحكم علي مدي جدوي

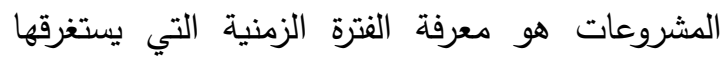

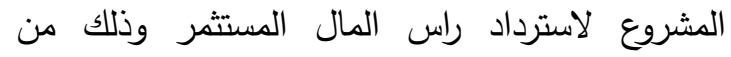

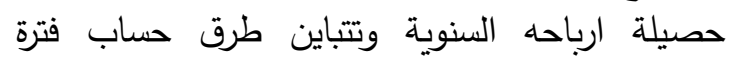
الاسترداد بصور رياضية مختلفة واستخدمت الدراسة في حسابها الصورة الأتية: فترة الاسترداد= إجمالى الاستثمارات مقسوما علي متوسط الربح السنوي النقدي. ويتبن من نتائج المعادلة أن فترة الاسترداد للصصانع

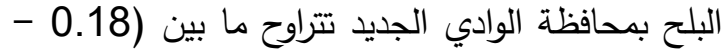
7.71) سنه وهى فترة جيدة لاسترداد تكاليفه 
وتوضح النتائج بالجدول (9) أن سعر التعادل

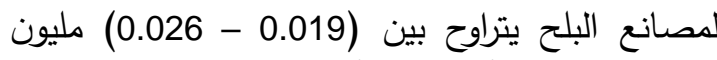
جنية / طن كد أدنى وحد أعلى على الترتيب.

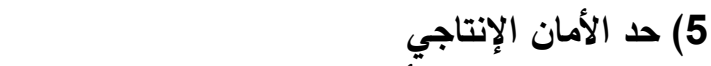

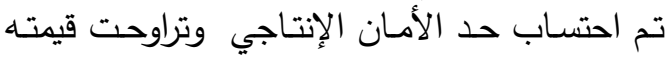

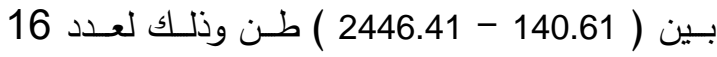
مصنعا خاصة بصناعة البلح.

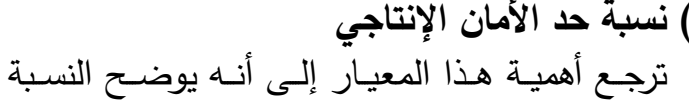

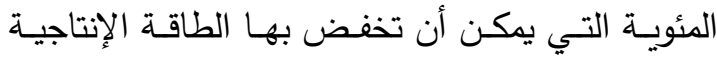

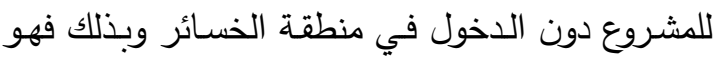

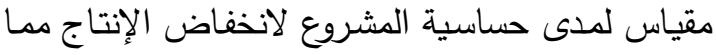

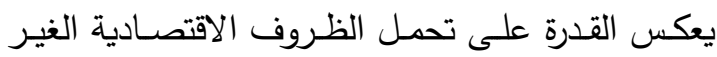
مواتية، ويتم حسابه وفقا للمعادلة التالية :

الإنتاج السنوي - الإنتاج عند حجم التعادل

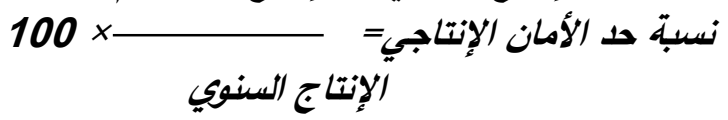

وقد تبين أن نسبة حد الأمان الإنتاجي لكصانع

البلح بالمحافظة يتراوح بين(32.18يبين قدرة مصانع تعبئة وتغليف البلح على مواجهة ظروف الدخاطرة المحتملة من انخفاض الإنتاج أو الو

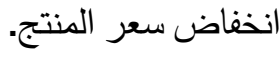

ويعبر هذا المعيار عن القيمة المتبقية من إيرادات

\section{(7) - حد المساهمة}

المبيعات بعد تغطية التكاليف التثغيلية لمصانع العينة

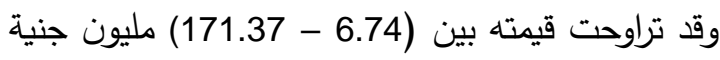

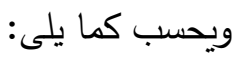

$$
\begin{aligned}
& \text { حـ المساهمة = المبيعات - التكاليف التشغيلية } \\
& \text { 8) معدل حد المساهمة }
\end{aligned}
$$

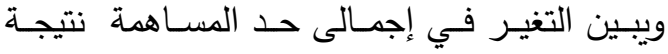

$$
\begin{aligned}
& \text { لزيادة قيمة المبيعات بجنية واحد و قد تراوحت بين حد النداهي }
\end{aligned}
$$

2) معيار نقطة التعادل للقيمة وتحسب رياضيا من المعادلة التالية:
وتوضح النتائج بالجدول رقم (9) أن نقطة التعادل

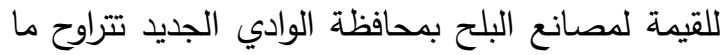

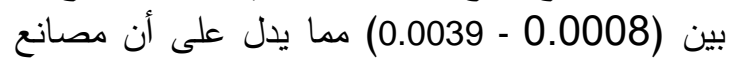
البلح بمحافظة الوادي الجديد من المشاريع المؤمنة من الن بان

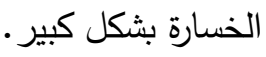

3) كمية التعادل

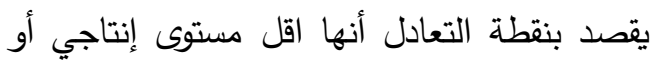

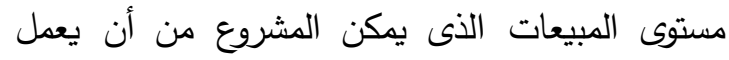

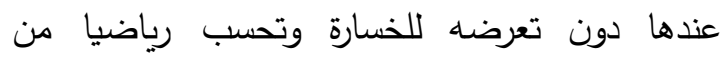

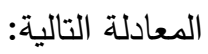
كمية التعادل = الإجمالي العام للتكاليف / سعر بيع وقد تبين أن كميـة التعـادل لمصانع البلح تتراوح

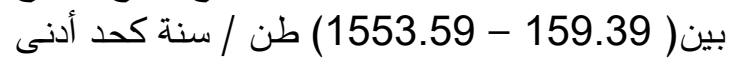
وأعلى على الترتيب لـصانع تمثل طاقتها الإنتاجية ما

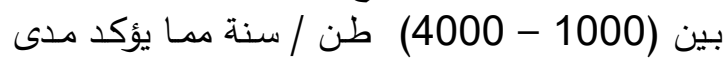
أربحيـة هذه المصانع وتباين طاقتها الإنتاجية بفـارق كبير

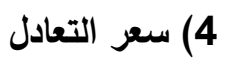
هو ذلك السعر الذى يتساوى عنده تكاليف وإيرادات

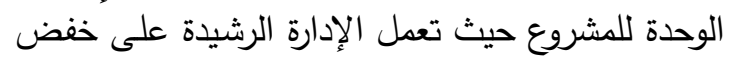
تكاليف الوحدة للمشروع لأقل من سعر التُارن التعادل فارتفاع

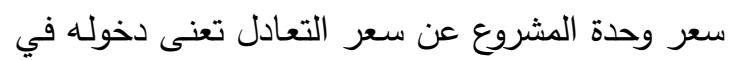
منطقة الخسائر ، ويتم حسابه وفقا للمعادلة التالية :

$$
\text { سعر التعادل = إجمالى التكاليف الإنتاج }
$$


يعكسان مدى تشغيل الأيدي العاملة التي تهتم بها الدولة،

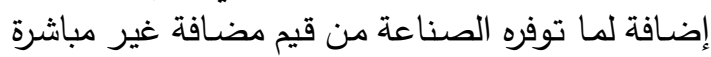

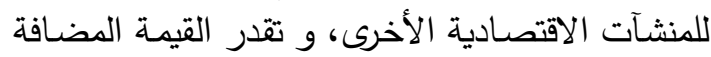

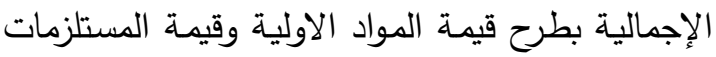
السلعية والخدمية من قيمة الانتاج، وعليه فإن: الإلية الإلية

القيمة المضافة الإجمالية = قيمة الانتاج- قيمة المواد الاولية (قيهة المستلزمات السلعية وإلخدمية) غير متضمنة الأجور. يتبين من جدول رقم (10) أن أعلى قيمة مضافة

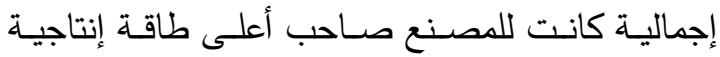

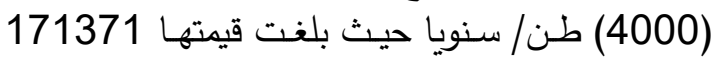
ألف جنية، وبينما بلغت أقل قيمة مضـافة 6735 وذلك لمصنع بلغت طاقته الإنتاجية 400 طن /سنويا. من خـلال معيار القيمة المضافة الإجمالية يمكن

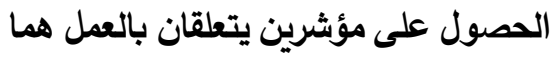

1 - مؤشر عدد العمال:((القيمة المضافة للعامل) يظهر هذا المؤشر مقدار القيمة المضافة التي المئي يعطيها كل عامل، حيث أن:

مؤشر عدد العمال = الثقيمة المضافة الإجمالية عدل العمال

وتوضح النتائج بالجدول رقم (10) أن مؤشر عدد

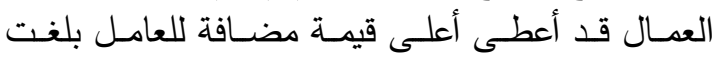
1760.68 جنية في حين أن أدنى قيمة مضافة لكل الفل عامل قد بلغت 166.34جنية.

يقيس مؤشر الأجور إنتاجية عنصر العمل ومعرفة

$$
2 \text { - مؤشر الاجور }
$$

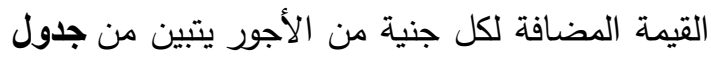
رقم (10) أن أعلى قيمة مضافة لكل جنية من الأجور قد الأد بلغت 64.32 جنية، في حين بلغت أدنى قيمة مضافة الأنة لكل جنية من الأجور نحو 7.73 جنية.
أدنسى بلـنغ 37.77\% وحـد أعلى بلـن 62.95 \% ويحسب كالتالي: - الي

معدل حد المساهمة = حد المساهمة / إجمالى الإيراد/ت 100

$$
\text { 9) العائد على الجنيه }
$$

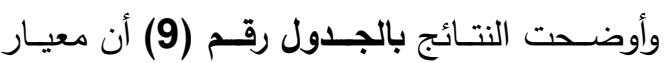

العائد على الجنية قد تراوح ما بين حد أدنى بلغ 1.50

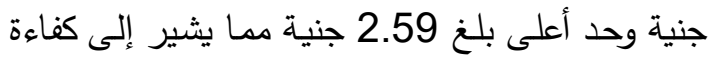
المصانع الاقتصادية، ويحسب كما يلى

$$
\text { العائد على الجنية = الربح / التكاليف الكلية }
$$

10) - 10 نسبة هامش الربح يمكن حساب نسبة هامش الربح كالآتي:

نسبة هامش الربح = 1- ( إجمالى التكاليف المتغيرة | إجمالـى الإيراد/ت العامة ).

ويتضح من نتائج هذا المعيار بالجدول رقم (9) أن

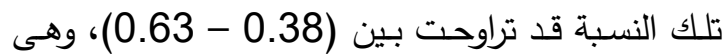
نسبة مرتفعة تثير إلى أربحية تلك المشاريع.

التقييم الاقتصادي والاجتماعي لصناعة تعبئة وتغليف البلح بمحافظة الوادي الجديد

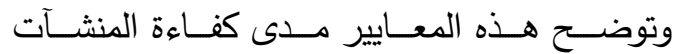

الصناعية من حيث استخدام مدخلاتها أو طريقة إداء الصناء

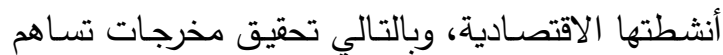

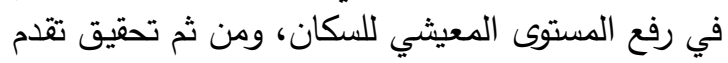

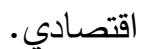

وفيما يلى عرضا لمعايير التقييم الاقتصادي

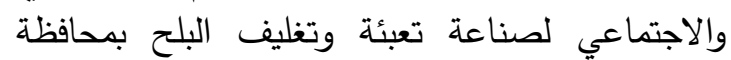

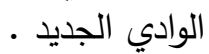

أولا : معيار القيمة المضافة الإجمالية

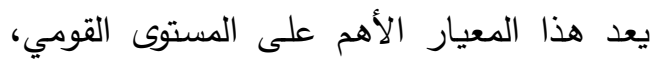

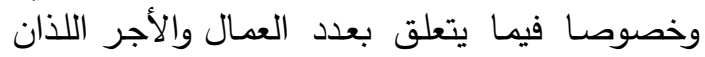




$$
\text { إلهام أحمد - السنتريسى - عبد المقصود }
$$

جدول 9. معاير تقييم أداء صناعة تعبئة وتغليف البلح بمحافظة الوادي الجديد عام 2019

\begin{tabular}{|c|c|c|c|}
\hline الحد الأعلى & الحد الأدنى & \multicolumn{2}{|l|}{ 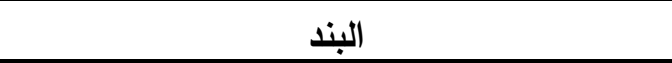 } \\
\hline 2.59 & 1.50 & نسبة المنافع للتكاليف (دليل الربحية) & \\
\hline 70.6 & 90.3 & نسبة التكاليف المتغيرة إلى الإيرادات & E \\
\hline 7.71 & 0.18 & فترة الاسترداد & \\
\hline 0.63 & 0.38 & نسبة هامش الربح & \\
\hline 0.12 & 0.02 & معيار نقطة التعادل للكميه & \\
\hline 6.47 & .111 & معيار نقطة التعادل للقيمة & $f:$ \\
\hline 0.026 & 0.019 & (مليون جنية) & $\underline{s}$ \\
\hline 1553.59 & 159.39 & كمية التعادل & \% \\
\hline 104.94 & 6.77 & (مليون جنيه) & \\
\hline 2446.41 & 140.61 & حد الأمان الإنتاجي & $\frac{\sigma}{6}$ \\
\hline 61.16 & 32.18 & نسبة حد الامان الإنتاجى \% & \\
\hline 171.37 & 6.74 & حد المساهمة & $\xi$ \\
\hline 62.95 & 37.77 & معدل حد المساهمة & \\
\hline 2.59 & 1.50 & العائد على الجنيه & \\
\hline
\end{tabular}

المصدر: جمعت وحسبت من جداول التكاليف من رقم (6 إلى 11) باستخدام برنامج Excel .

\section{إنتاجية المواد الأولية والمستلزمات السلعية وإلخدمية قيمة الإنتاج}

قيمة المواد الأولية والمستلزمات السلعية وإلذدمية

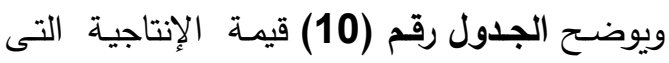

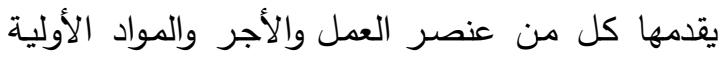
والمستلزمات السلعية والخدمية لصناعة تعبئة وتغليف الصنا

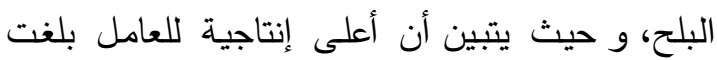

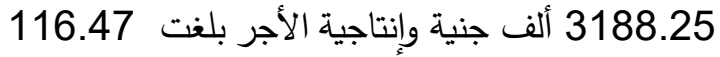
ألف جنية في حين أدنى إنتاجية للعامل بلغت 440.40

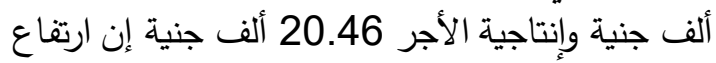

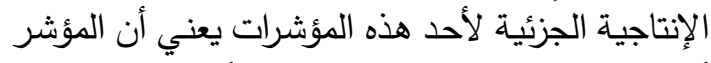

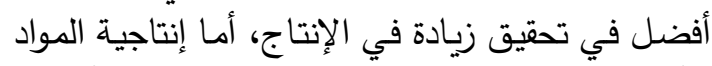

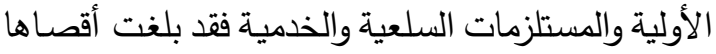
2.70 ألف جنية، في حين بلغت أدنى إنتاجية 1.61

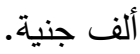

حيث يعبر هذا المؤشر عن مقدار الزيادة التي تحدث في القيمة المضافة نتيجة للزيادة في الأجور ، لزئن

\section{مؤشر الاجور = القبية الاجمالية المضافة} قبية الاجور

ثانيا : معيار الانتاجية الجزئية تم حساب معيار الإنتاجية الجزئية لكل من إنتاجية العامل وإنتاجية الأجر، وإنتاجية الموارد الأولية في الإنية التئية عملية التقييم نظرا لتوافر بياناته في استمارة الاستبيان عن عدد العمال وقيمة الأجور والموارد الأولية كالاتي:

$$
\begin{aligned}
& \text { انتاجية العامل = قدية الانتاج } \\
& \text { إنتاجية الأجر = قيمة الإنتاجة }
\end{aligned}
$$


جدول 10. بعض معايير التقييم الاقتصادي والاجتماعي لمصانع تعبئة وتغليف البلح بمحافظة الوادي الجديد (بالمليون جنية)

\begin{tabular}{|c|c|c|c|c|c|c|c|c|}
\hline \multicolumn{8}{|c|}{ معايير كفاءة الأداء الاقتصادي والاجتماعي } & \multirow[b]{2}{*}{ b } \\
\hline فرصل الإجمالية & فرصة & إلتاجية المواد & الأجتاجية & إلعاملية & مؤشر & مؤشر & معيار القيمة المضافة & \\
\hline 0.18 & 5.61 & 2.70 & 76.48 & 2.62 & 48.14 & 1.65 & 171.37 & 1 \\
\hline 3.09 & 0.32 & 2.64 & 78.16 & 2.62 & 48.54 & 1.63 & 117.33 & 2 \\
\hline 3.13 & 0.32 & 2.23 & 116.47 & 3.19 & 64.32 & 1.76 & 70.43 & 3 \\
\hline 4.84 & 0.21 & 2.15 & 59.90 & 1.55 & 32.01 & 0.83 & 49.64 & 4 \\
\hline 7.07 & 0.14 & 1.75 & 30.57 & 0.66 & 13.13 & 0.28 & 23.99 & 5 \\
\hline 7.17 & 0.14 & 1.92 & 33.16 & 0.67 & 15.91 & 0.32 & 25.80 & 6 \\
\hline 0.48 & 2.08 & 1.97 & 36.95 & 0.58 & 18.20 & 0.29 & 25.75 & 7 \\
\hline 6.28 & 0.16 & 1.83 & 36.00 & 0.74 & 16.36 & 0.34 & 20.12 & 8 \\
\hline 3.42 & 0.29 & 2.25 & 47.26 & 1.72 & 26.29 & 0.96 & 23.92 & 9 \\
\hline 6.19 & 0.16 & 1.86 & 23.73 & 0.69 & 10.97 & 0.32 & 17.56 & 10 \\
\hline 5.76 & 0.17 & 1.61 & 20.46 & 0.44 & 7.73 & 0.17 & 12.48 & 11 \\
\hline 5.02 & 0.20 & 2.05 & 32.85 & 0.76 & 16.84 & 0.39 & 15.57 & 12 \\
\hline 3.08 & 0.32 & 1.73 & 36.10 & 1.21 & 15.26 & 0.51 & 7.69 & 13 \\
\hline 4.14 & 0.24 & 1.68 & 21.85 & 0.57 & 8.81 & 0.23 & 6.84 & 14 \\
\hline 1.96 & 0.51 & 1.96 & 22.54 & 0.60 & 11.02 & 0.29 & 7.94 & 15 \\
\hline 4.23 & 0.24 & 2.09 & 21.26 & 0.52 & 11.10 & 0.27 & 6.74 & 16 \\
\hline
\end{tabular}

المصدر: استمارة الاستبيان المعدة لبنود التكاليف والإيرادات والتي تم استيفائها عن طريق المقابلة الثخصية لأصحاب

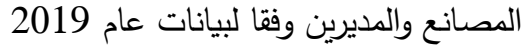

أوضحت نتائج استمارة الاستبيان ما تم حصره من مشاكل تواجه صناعة تعبئة وتغليف البلح بمحافظة التئة الوادي الجديد، والتي يمكن حصرها في:

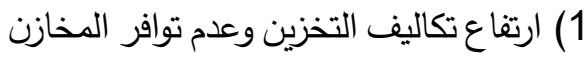
2) زيادة السعر لا تلتاسب مع تكاليف التخزين . 3) تعرض الثمار للتلف أثناء عملية النقل.

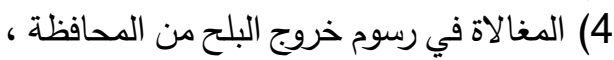

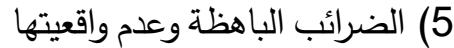

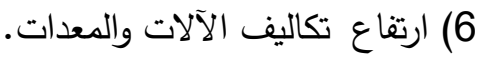
7) ارتفاع تكاليف مواد التعبئة والتغليف.
ثالثاً: تكلفة خلق فرص العمل

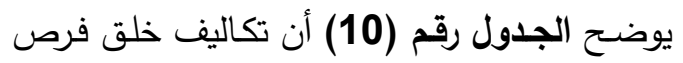

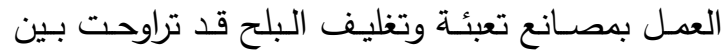

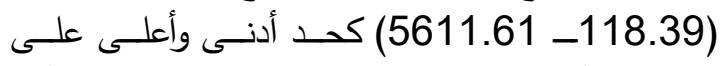

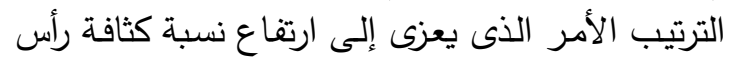

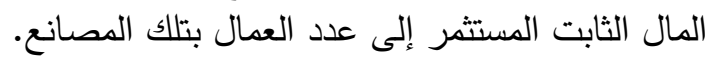

المشاكل التي تواجه صناعة تجهيز وحفظ البلح بمحافظة الوادي الجديد 
والعمل على رفح المستوى التقتي لتلك الصـناعة مـع تزويدها بالعمالة الفنية المدربة، وكذلك ضـرورة الاهتمام

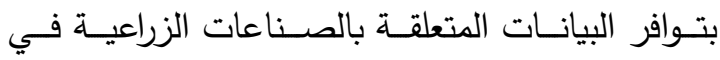

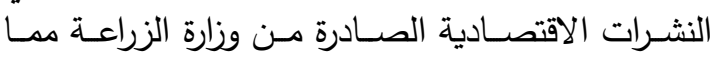

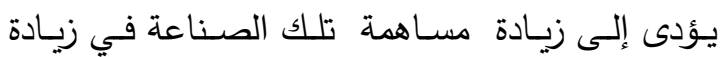
الاخل القومي من خلال أتباع النقاط الآتية: 1) ضرورة خفض أسعار البيع للمستهلك للمساهمة في

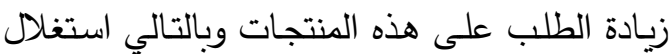

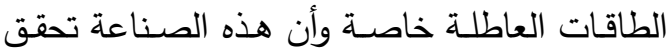

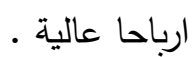
2) الترويتج لمثل هذا النشاط وتشجيع الاستثمار فيه من فن خلال منح تسهيلات واعفاءات للمنتجين 3) الاستغلال الأمثل للطاقات التصنيعية العاطلة مـع تقليل الفاقد

4) تصميم برنامج لتحديث الوحدات التصنيعية الزراعية التقليدية.

5) تخطيط وتتفيذ برنامج للنهوض بالتصنيع الريفي.

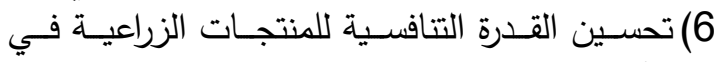
الأسواق المحلية والدولية.

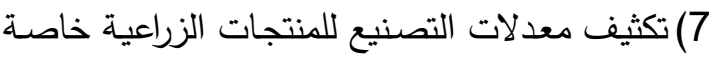
صناعة تجهيز وحفظ البلح. 8) تحسين مناخ الاستثمار الزراعي لإتاحة فرصن العمل العمل بمحافظة الوادي الجديد.

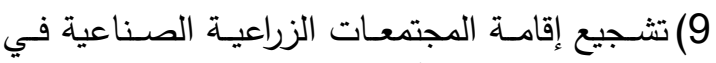
المناطق الريفية والأراضي المستصلحة.

المراجـع

أولا: المراجع العربية

أمال عبد المنعم عبدالحميد محمد 2013. اقتصاديات تصنيع البلح في مصسر، قسـم الاقتصساد الزراعي،

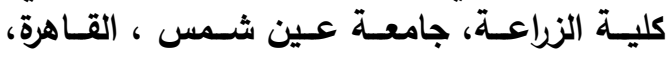

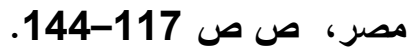
ريتشارد بروتسون 1988. 117. بحوث العمليات، سلسلة ملخصات شوم، الترجمة العربية، الطبعة الأولى، القاهرة، مصر ، ص ص ص 156-186.
8) عدم إجرائهم لعملية التبخير ومقاومة سوسة البلح نظرا لارتفاع أسعار التبخير بالإضافة قلة الخبرة في

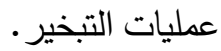

9) مساومتهم علي الأسعار وطلبهم لدفع الثمن فورا.

10) منافسة الدول العربية في الجودة والأسعار •

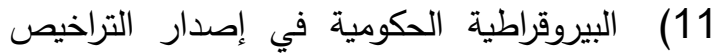
والأوراق الخاصة بتسجيل المنشأة.

التوصيات والمقترحات

أولا: توصيـات عامة للنهوض بالتصنيع الزراعي

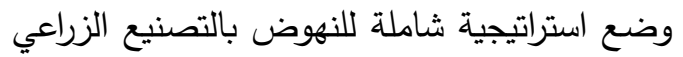
في كافة مراحل التصنيع بدءًا من الزراعة ثم التصنيع والتعبئة والتغليف والتسويق كالتالي: 1- زراعة أصناف خضر وفاكهة مناسبة للتصنيع بما يرفع من جودة المنتج الصناعي.

2- استخدام التكنولوجيا الحديثة في الزراعة بما يساهم في زيادة الإنتاج وتحسين جودته

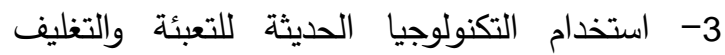
للمنتجات الزراعية للحفاظ عليها وتوفير الخدمات

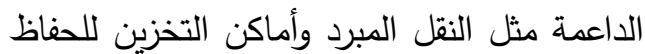
على جودة الإنتاج الزراعي.

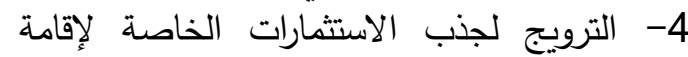

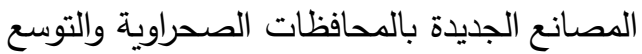
في الأنشطة الصناعية القائمة. 5- ضرورة العمل على زيادة نسب التشغيل لتقترب من الطاقة القصوى واستغلال الطاقة العاطلة ولو عن طريق تأجيرها. 6- طرح مساحات كبيرة للاستصلاح الزراعي لشركات

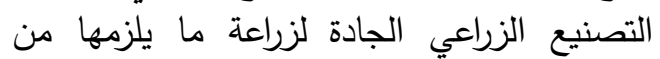

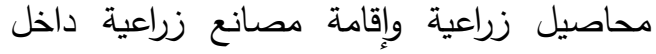
مناطق الاستصلاح الجديدة.

ثانيا: توصيات للنهوض بصناعة تجهيز وحفظ البلح بمحافظة الوادي الجديد

يوصسى البحث_بضـرورة العمل على الاهتمـام بتلك الجدئ

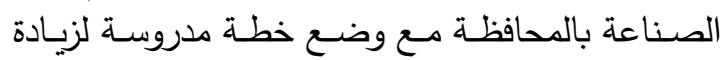

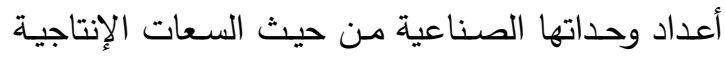

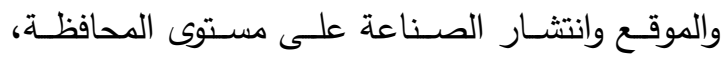


منير صالح هندي 1989. الإدارة المالية : مدخل تحليل

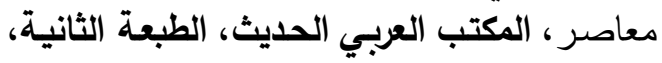

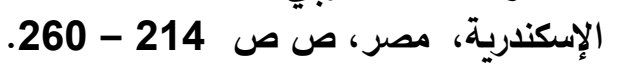

$$
\text { ثانياً : المراجع الاجنبية }
$$

Pandy, I.M. 1981. Financial Management, $2^{\text {nd }}$ Revised Ed., VIKAS Publishing House PVT, LTD., pp. 211- 257.

UNIDO 1978. Manual for the preparation of Industrial feasibility studies, United Nations, New York, USA, pp. 121 172.
عبد الله ثنيان الثنيان، كمـال سلطان محمد، 1992.

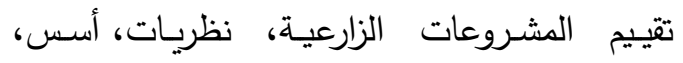

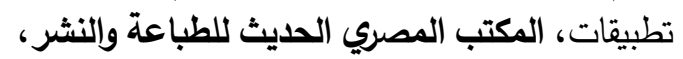

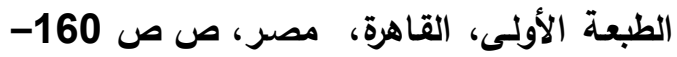
.167

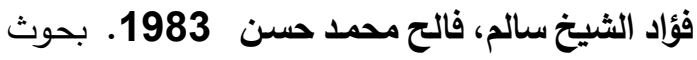

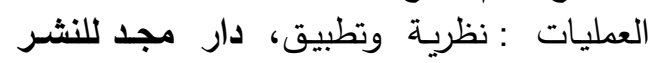

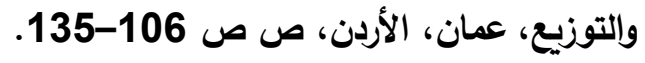

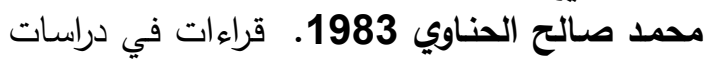

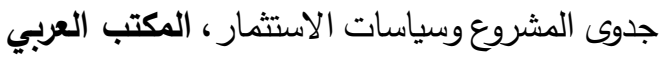

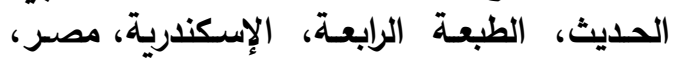

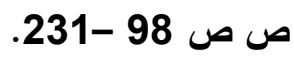


إلهام أحمد - السنتريسى - عبد المقصود

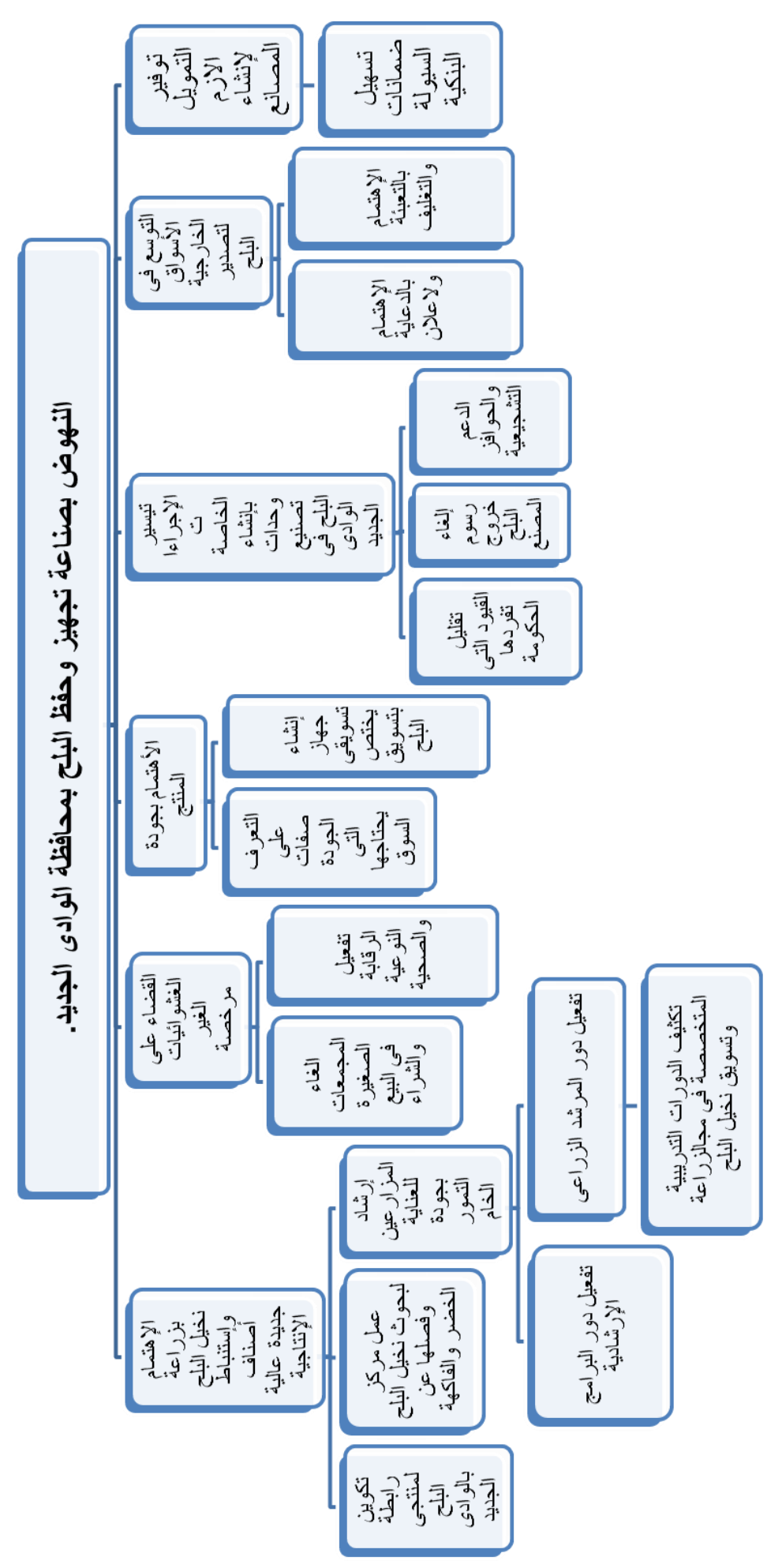




\title{
ECONOMIC EVALUATION OF THE PACKAGING INDUSTRY OF DATES IN NEW VALLEY GOVERNORATE (CASE STUDY)
}

\author{
Elham M.S. Ahmed ${ }^{\star}$, El Santrisi M.A. and Abdelmaqsoud A.M. \\ Agric. Economics Dept., Fac. of Agric., Ain Shams Univ., P.O. Box 68, Hadayek Shobra11241, \\ Cairo, Egypt \\ *Corresponding author: elham.yazed@yahoo.com
}

\section{ABSTRACT}

Projects of various sizes and types contribute to the success of the economic development plans in general. Agricultural industrial projects are the basis for agricultural development in the economies of many countries, so this research aims to identify the economic feasibility of one of the productive activities in the New Valley governorate, On the efficiency of the work in the manufacturing units and the possibility of expansion in the future establishment in addition to identify the implications of the establishment of those units.

The problem of research is that the packaging industry is very important because of its ability to absorb a large proportion of the labor force by creating many direct and indirect employment opportunities, from agriculture to storage of agricultural and industrial products that are produced to distribution to complementary industries such as Packaging The focus was on date factories as the main product of the New Valley Governorate. However, the expansion of these units has led to an imbalance between the production capacities and the availability of commodity inputs on the one hand, and the extent to which the revenues and investment profits of that unit.

The research aims to identify the current status of agricultural processing in the New Valley Governorate by identifying the number of factories, their relative importance and the activities of agroindustries, focusing on the most important activities of agro-industries and the importance of agricultural processing, especially in the field of date
\end{abstract}

industry. In addition to trying to identify the most important problems and obstacles that hinder the development of the industry of processing and preserving dates in the New Valley Governorate for the development of this sector by evaluating the factories that rely on agricultural products as raw material.

The questionnaire was prepared and completed by (16) establishments working in the field of packing dates, semi-automatic, The research data were collected in 2019 through a personal interview with the factory managers, The questionnaire included data on production values, raw materials, wages, commodity and service inputs, number of workers, ... etc., These data were analyzed using financial and economic criteria. As it achieves an annual trading profit ranging between (167.30-6.9) million pounds, which represents a commercial profitability ratio ranging from (1.50 - 2.59) pounds, which is a high percentage reflecting the profitability of this productive activity, while the income of the investor invested between $(0.50-1.59)$ pounds Which indicates the efficiency of this industry economically, while the value of the break-even point ranged from (6.77-104.94) million pounds, while the percentage of the margin safety of production ranged between $(32.18$ - 61.16)\%showed the ability of these manufacturing units to cope with the potential risk conditions of lower production. Or lower product price.

Keywords: Agricultural Processing, Financial Assessment, Margin of Safety, Cost Benefit Ratio, Packaging Of Dates.

$$
\text { تحكيم: ا.د أشرف شبل يونس }
$$


Hanaa Hussin; Nematallah Mohammed; Badri and Maie Ali

Arab Univ. J. Agric. Sci., 27(2), 2019 